\title{
O SUPERGRUPO ESPINHAÇO DA SERRA DO ESPINHAÇO MERIDI- ONAL (MINAS GERAIS): O RIFTE, A BACIA E O ORÓGENO
}

\author{
Pedro Angelo Almeida Abreu (*)
}

\begin{abstract}
The Serra do Espinhaço is a mountain chain built up mainly of quartzitic rocks of the Espinhaço Supergroup. It extends from the central part of Minas Gerais to the north of Bahia, a length of $1200 \mathrm{~km}$ in a N$\mathrm{S}$ direction. The southern part of the Serra do Espinhaço (SdEM), which is $300 \mathrm{~km}$ long, extends from Quadrilátero Ferrífero to Olhos d'Água (Fig. 1), and during its initial rifting phase of development was separated from the northern part by a NE-trending sinistral transfer fault system (Fig. 2).

The Guinda Group contains the synrift sedimentary and volcanic rocks of the SdEM (Tab. 1 and 2). The rifting processes were thermally controlled and started at $1750 \mathrm{Ma}$. The rifting evolved in 3 distinct phases: the first phase was marked by sedimentation of the Bandeirinha Formation (fluvio-eolian environments) with strong extensional activity that caused block tilting of the units of this formation and the exhumation of a core complex in the median-central part of the SdEM; during the second rifting phase the fluvial sediments of the São João da Chapada Formation were deposited, following minor thermal subsidence of the rift; an asthenospheric plume upwelling below the continental crust along the central part of the rift (Fig. 3) caused the third phase of rifting by intensive vertical block movements, generating half-grabens that propagated to the east. The fluvial and lacustrine sediments of the Sopa-Brumadinho Formation (Fig 4) mark this third phase of rifting. During the eastward propagation of the extensional tectonics (Fig. 5), the half-grabens were progressively filled up by eolian sediments of the Galho do Miguel Formation.

The crustal extension culminated in mantle-uncovering at the axial zone of the rift (Fig. 3), generally with serpentinization, and a marine basin was formed. Thick piles of clastic sediments and banded iron formations were deposited in the neritic and bathyal/abyssal zones, and at the same time the alluvial sediments (fan deltas) of the Sopa-Brumadinho Formation prograded out into the coastal parts of the basin (Fig. 6).

Because of the strong thermal subsidence of the basin, the locus of deposition of the marine coastal sediments was at least $80 \mathrm{~km}$ westward (Fig. 7), this being indicated by the occurrence of the Conselheiro Mata Group (Tab. 1) in the western part of the SdEM. The thermal subsidence of the basin marks the start of the Espinhaço passive continental margin and the end of rift-forming processes.

Tectonic inversion started at about $1.5 \mathrm{Ga}$ with eastward subduction of oceanic crust, and this preceded the continental collision that built up the SdEM. The units of the Espinhaço Supergroup in the western and central parts of the orogen were folded in N-S trending open folds during the initial phase of the tectonic inversion. The deformation related to the subsequent collision was strongly partitioned, consequent both on the plate indentation and on transcurrent/strike-slip fault movements (Fig. 8, 9 and 10).

In the proximal collision zone (eastern edge of the SdEM), a thrust belt developed, and in the southcentral part of the SdEM and the eastern region of the Quadrilátero Ferrífero the thrust sheets propagated onto the western domain of the orogen, destroying either partially or totally the previous folding system (Fig. 9 and 11).

The wandering of the São Francisco craton through high latitudes at about $1.05 \mathrm{Ga}$ caused a mountain glaciation in its higher parts, as indicated by the meta-tillites of the Macaúbas Group and equivalent units.

Around $2.5 \%$ of the SdEM surface is formed of basaltic rocks derived from basic magmatism ( $906 \mathrm{Ma}$ ) that preceded the fragmentation of the continental mass that had been amalgamated by the end of Mesoproterozoic time. This continental fragmentation formed the Neoproterozoic basins of the western African continent and caused extensive subsidence of São Francisco craton. A large epicontinental basin was developed there, now indicated by units of Bambuí Group (Fig. 1).

The orogenesis of the West Congolian belt ( 750-500 Ma) caused a strong reactivation of the Espinhaço System, with the units of the Macaúbas and Bambuí groups being overthrusted by sequences of the Espinhaço Supergroup (Fig. 9 and 11). The westward subduction of the oceanic plate of the West Congolian basin under the southeastern edge of the São Francisco craton (Fig. 12) is indicated by the size and frequency of granitic plutons in the eastern parts of the Araçuaí belt and SdEM, as well as by thermal event of Brasiliano age that is recorded in metamorphic and granitic rocks over the whole eastern part of this craton.
\end{abstract}

\section{INTRODUÇÃO}

O Nucleo-MG da Sociedade Brasileira de Geologia, no ensejo do $8^{\circ}$ Simpósio de Geologia de Minas Gerais, revive, 16 anos depois, o tema do seu $1^{\circ}$ simpósio realizado em 1979, "A Cordilheira do Espinhaço".

Nesse lapso de tempo, o progresso no conhecimento da geologia da Serra do Espinhaço foi significativo, tanto pelos trabalhos adicionais no âmbito dessa região, como pela aplicação dos conceitos modernos da ciência geológica nos campos da geologia estrutural, sedimentologia, geotectônica e evolução crustal.

Isso permitiu a elaboração de modelos de evolução geotectônica e/ou geodinâmica para a Serra do Espinhaço pelos pesquisadores que desenvolvem trabalhos no domínio dessa serra. 
Este autor propôs, recentemente, um modelo de evolução geodinâmica para o segmento meridional da Serra do Espinhaço (Almeida Abreu 1993, Almeida Abreu \& Pflug 1994) e como convidado para a Mesa Redonda deste Simpósio "A Evolução Geológica da Cordilheira do Espinhaço" apresenta a síntese de tal modelo à luz dos novos dados obtidos em trabalhos de pesquisa em desenvolvimento no âmbito desse orógeno.

\section{CONTEXTO GEOLÓGICO REGIONAL}

A Serra do Espinhaço Meridional (SdEM) representa uma faixa orogênica que limita o sudeste do Craton do São Francisco. Amalgama-se, para nordeste, com a Faixa Araçuaí e mostra-se segmentada e deslocada em relação à parte setentrional dessa serra (Fig. 1). A SdEM estende-se por cerca de $300 \mathrm{Km}$ na direção N-S, desde o Quadrilátero Ferrífero até a região de Olhos d'Água e é edificada essencialmente por litologias do Supergrupo Espinhaço (principalmente rochas quartzíticas e, subordinadamente, rochas filíticas, conglomeráticas e vulcânicas de caráter básico e ácido.

Atualmente existem centenas de artigos, relatórios e teses abordando a geologia da Serra do Espinhaço. Os leitores interessados em obter sínteses e referências desses trabalhos devem consultar Renger (1979, 1995-neste volume), Uhlein (1991) e Almeida Abreu (1989, 1993).

\section{ESTRATIGRAFIA}

A SdEM mostra 3 conjuntos tectonoestratigráficos maiores: o Complexo Basal e os supergrupos Rio Paraúna e Espinhaço (Tab.1). Além

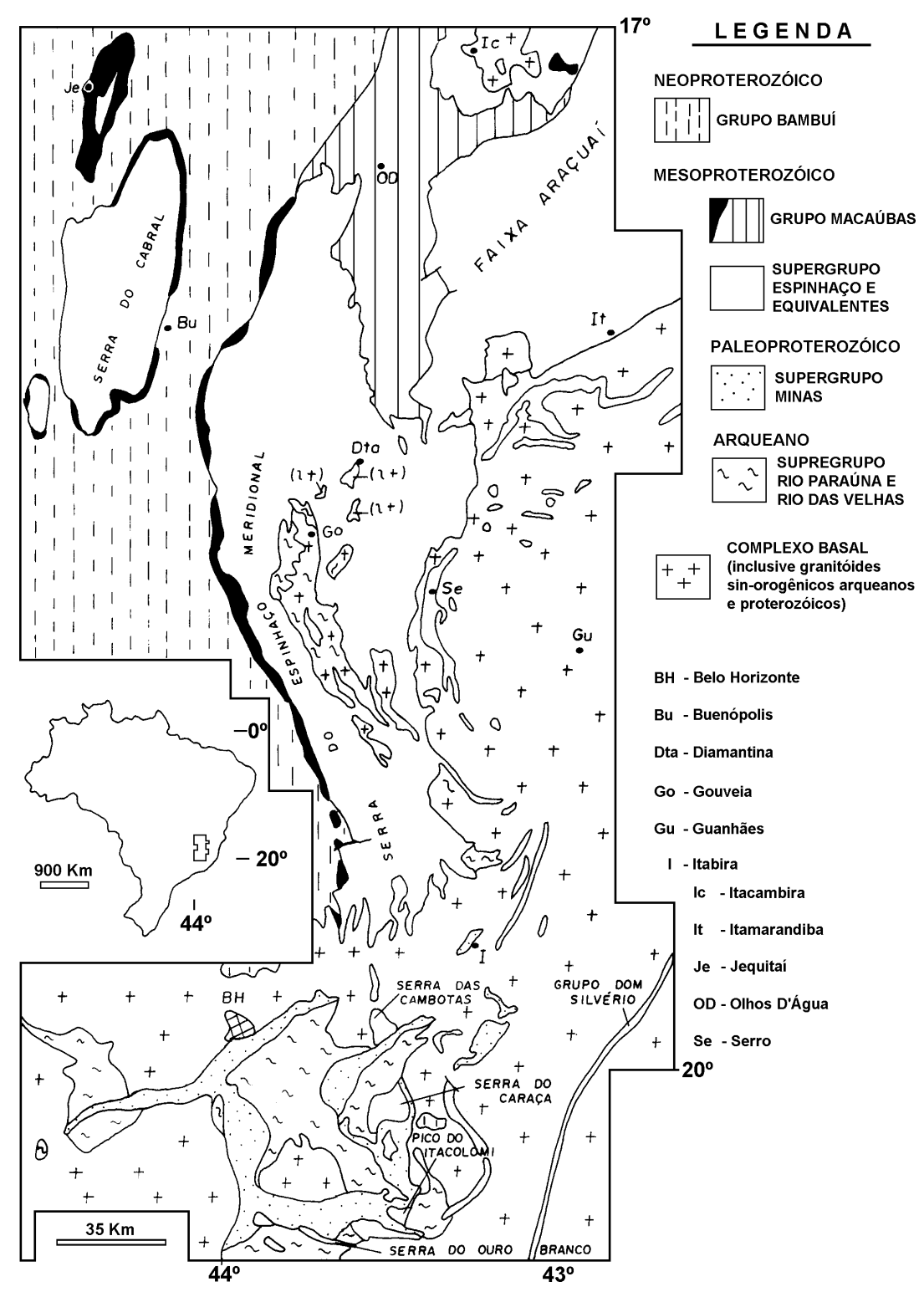

Figura 1: Mapa de situação da Serra do Espinhaço Meridional (SdEM).

Figure 1: Location map of the southern Serra do Espinhaço (SdEM). 


\begin{tabular}{|c|c|c|c|c|}
\hline \multirow{10}{*}{ 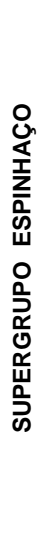 } & GRUPO & FORMAÇÃO & LITOLOGA & $\begin{array}{l}\text { ESPESSURA } \\
\text { (MEROS) }\end{array}$ \\
\hline & \multirow{5}{*}{ 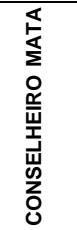 } & 9 - RIO PARDO GRANDE & PEITOS, ARENITOS, LOCALMENTE CARBONATOS & $60-1000 ?$ \\
\hline & & 8 - CÓRREGO PEREIRA & $\begin{array}{l}\text { ARENITOS (PUROS, MICÁCEO OU FELDSPÁTICO), } \\
\text { LOCALMENTE PELITOS }\end{array}$ & $\sim 250$ \\
\hline & & 7 - CÓRREGO DA BANDEIRA & PELITOS, ARENITOS & $100-200$ \\
\hline & & 6 - CÓRREGO DOS BORGES & $\begin{array}{l}\text { ARENITOS (PUROS OU MICÁCEOS), LOCALMENTE } \\
\text { BRECHA / CONGLOMERADOS QUARTZITICOS }\end{array}$ & $\sim 100$ \\
\hline & & 5 - SANTA RITA & PELITOS, SUBORDINADAMENTE ARENITOS & $100-250$ \\
\hline & \multirow{4}{*}{ 衣 } & 4 - GALHO DO MIGUEL & $\begin{array}{l}\text { ARENITOS, LOCALMENTE LEITOS PELÍTICOS } \\
\text { DELGADOS }\end{array}$ & $500-3000 ?$ \\
\hline & & 3 - SOPA BRUMADINHO & VERTABE-A 2 & $0-250$ \\
\hline & & 2 - SÃO JOÃO DA CHAPADA & $\begin{array}{l}\text { ARENITOS (MÉDIOS A GROSSEIROS, PUROS OU } \\
\text { MICÁCEOS), FILITOS HEMATÍTICOS, } \\
\text { CONGLOMERADO/BRECHA BASAL }\end{array}$ & $0-300$ \\
\hline & & 1 - BANDEIRINHA & $\begin{array}{l}\text { ARENITOS PUROS OU MICÁCEOS (INCLUINDO RED } \\
\text { BEDS), CONGLOMERADOS (SUBORDINADO), } \\
\text { LOCALMENTE BRECHAS E PELITOS. }\end{array}$ & $0-200$ \\
\hline
\end{tabular}

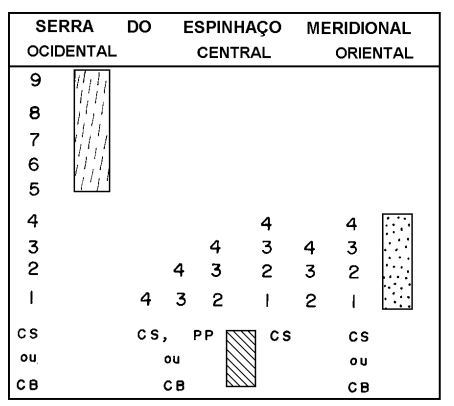

\begin{tabular}{|c|c|c|c|}
\hline \multirow{2}{*}{ 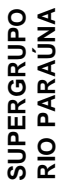 } & $\begin{array}{l}\text { GRUPO COSTA SENA } \\
\text { (CS) }\end{array}$ & $\begin{array}{l}\text { SERICTA / MUSCOVITA XISTOS OOM } \pm \text { QUARTZO, } \\
\text { CIANTA OU TURMALNA E SUBORDINADAMENTE } \\
\text { QUARTZO XISTOS, QUARTZTOS EVULCÂNICAS } \\
\text { ÁCIDAS OUBÁSICAS }\end{array}$ & $0-600$ \\
\hline & $\begin{array}{l}\text { GRUPO PEDRO PEREIRA } \\
\text { (PP) }\end{array}$ & $\begin{array}{l}\text { TALCO XISTOS COM } \pm \text { CLORTA E ACTINOLTA / } \\
\text { TREMOLITA, SERPENTINITOS, CLORITA XISTOS, } \\
\text { FORMACÕ̃ES FERRRIFAAS BANDADAS, LOCALMENTE } \\
\text { MICA XISITOS E VULCÂNICAS ÁCIDAS }\end{array}$ & $0-250$ \\
\hline
\end{tabular}

\begin{tabular}{|l|ll|}
\hline \multirow{2}{*}{$\begin{array}{l}\text { COMPLEXO } \\
\text { (CB) BASAL }\end{array}$} & GRANITO DE GOUVEA & GRANITOS, GRANODIORTOS, TONALTOS \\
\cline { 2 - 3 } & GRUPO CONGONHAS & GNAISSES, MIGMATITOS, LOCALMENTE DIORITO \\
\hline
\end{tabular}

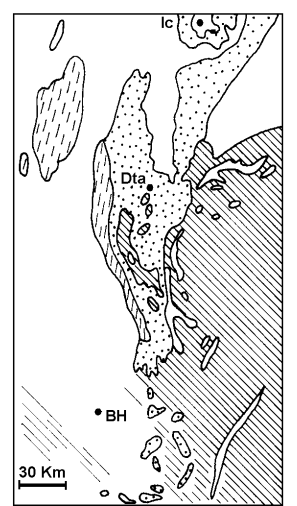

Tabela 1: Estratigrafia da SdEM, segundo Almeida Abreu \& Pflug (1994).

Table 1: Stratigraphic synthesis of the southern Serra do Espinhaço (compiled and modified from different sources by Almeida Abreu \& Pflug 1994).

\begin{tabular}{|c|c|c|c|c|}
\hline \multirow{4}{*}{ 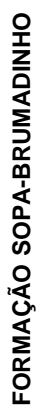 } & MEMBRO & FÁCIES & LITOLOGIA & ESPESSURA \\
\hline & $\begin{array}{l}\text { CAMPO } \\
\text { SAMPAIO }\end{array}$ & $\begin{array}{l}\text { LACUSTRE } \\
\text { SUPERIOR }\end{array}$ & $\begin{array}{l}\text { PRINCIPALMENTE PELITOS (LOCALMENTE COM NÍVEIS } \\
\text { RICOS EM TURMALINA), ARENITOS (MICÁCEOS OU NÃO), } \\
\text { DIAMICTITOS (EMLEITOS OU PREEN CHENDO } \\
\text { PALEOCANAIS). FILITOS HEMATITICOS E VULCÂNICAS } \\
\text { BÁSICAS }\end{array}$ & $0-60$ \\
\hline & CALDEIRÕES & $\begin{array}{l}\text { ALUVIAL / } \\
\text { LEQUES }\end{array}$ & $\begin{array}{l}\text { ARENITOS (PUROS, MCÁCEOS OU FERRUGINOSOS), } \\
\text { ARENITOS CONGLOMERÁTICOS, CONGLOMERADOS } \\
\text { POLI-OU-MONOMITICOS GERALMENTE SUPORTADOS PELOS } \\
\text { SEIXOS, FILITOS HEMATÍTICOS E XISTOS VERDES. }\end{array}$ & $50-150$ \\
\hline & DATAS & $\begin{array}{l}\text { LACUSTRE } \\
\text { INFERIOR }\end{array}$ & $\begin{array}{l}\text { PRINCIPALMENTE PELITOS, SUBORDINADAMENTE } \\
\text { ARENITOS, LOCALMENTE XISTOS VERDES E/OU FILITOS } \\
\text { HEMATITICOS }\end{array}$ & $0-100 ?$ \\
\hline
\end{tabular}

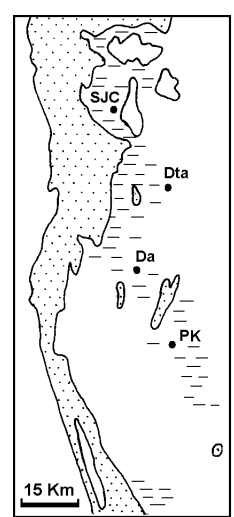

Tabela 2: Estratigrafia e faciologia da Formação Sopa-Brumadinho na faixa mediana-central da SdEM, segundo Almeida Abreu \& Pflug (1994).

Table 2: Stratigraphy and faciology of the Sopa-Brumadinho Formation on the median-central part of the SdEM (after Almeida Abreu \& Pflug 1994).

destes, aparecem bordejando essa serra, e mesmo sobrepondo localmente suas faixas limítrofes, unidades dos grupos Macaúbas e Bambuí (Fig.1).

O Complexo Basal ocupa parte da faixa medianacentral da SdEM onde é representado predominantemente por rochas graníticas s.s. (o Granito de Gouveia) que circunscrevem "manchas" ocasionais de rochas gnáissicas-migmatíticas mais antigas (Grupo Congonhas de Hoffmann 1983), conforme denunciado pelas relações de contato entre essas 2 unidades. Datação geocronológica do granito de Gouveia pelo método U/Pb em zircões revelou idades de cristalização da ordem de $2.839 \pm 14 \mathrm{Ma}$ (Machado et al 1989) confirmando a idade Arqueana dessa entidade. No leste e sul da SdEM o Complexo Basal é representado predominantemente por diferentes tipos de gnaisses e, subordinadamente, por granitos, charnoquitos e granulitos. Nessa região as rochas desse complexo mostram idades arqueanas, paleoproterozóicas e, localmente, idades mesoprotero-zóicas e neoproterozóicas (Teixeira et al. 1990 e referências por eles citadas).

O Supergrupo Rio Paraúna (Fogaça et al. 1984) representa uma sequência supracrustal e aflora apenas na faixa mediana-central da SdEM e, localmente, na borda sudeste desta serra. A unidade inferior - Grupo Pedro Pereira - tem distribuição areal muito restrita e é representada por uma complexa associação de rochas meta -máficas, -ultramáficas, -ácidas e metassedimentos de origem química (BIF's e metacherts) mostrando, invariavelmente, contatos tectônicos com as rochas do Complexo Basal. A unidade superior - Grupo Costa Sena - é a principal unidade deste supergrupo, em termos de distribuição areal, e reúne uma espessa sequência de sericita-xistos com quantidades variadas de quartzo e, frequentemente, de cianita. Eventualmente contém também lazulita, turmalina e hematita (Tab.1). Datação de zircões de metariolitos que ocorrem intercalados em unidades do Grupo Pedro Pereira revelaram idades da ordem 
de $2.971 \pm 16 \mathrm{Ma}$ (Machado et al. 1989).

As litologias do Supergrupo Espinhaço dominam amplamente a superfície da SdEM. Este supergrupo é dividido em 2 unidades principais: os grupos Guinda e Conselheiro Mata (Tab. 1 e 2).

O Grupo Guinda, termo introduzido por Knauer (1990), em substituição ao Grupo Diamantina de Dossin et al. (1985), reúne as formações São João da Chapada, Sopa-Brumadinho e Galho do Miguel. Almeida Abreu (1993) e Almeida Abreu \& Pflug (1994) incluíram, na base do Grupo Guinda (v. Tab. 1) a Formação Bandeirinha, considerada até então como unidade de topo do Supergrupo Rio Paraúna. Este grupo agrega uma espessa sequência de sedimentos de origem continental, com metavulcanitos intercalados, relacionados à fase rifte da Bacia Espinhaço.

O Grupo Conselheiro Mata (Dossin et al. 1985) reúne as 5 formações superiores do Supergrupo Espinhaço (Tab. 1) e representa uma espessa pilha de sedimentos de origem marinha costeira com alguma contribuição de sedimentos de origem continental (Almeida Abreu 1993 e referências por ele citadas).

Uma significativa quantidade de rochas metabasálticas (geralmente diabásio, microgabros e equivalentes) ocupam cerca de 2,5\% da superfície areal da SdEM (Hoppe 1986) na forma de diques, sills, stocks e soleiras. As relações estratigráficas e estruturais destas rochas ígneas mostram claramente que são pós-tectônicas em relação ao Supergrupo Espinhaço e datações de zircão e badeleita num corpo aflorante na região de Pedro Lessa revelaram idades da ordem de $906 \pm 2 \mathrm{Ma}$ (Machado et al. 1989).

O Grupo Macaúbas é aqui considerado no mesmo sentido de Almeida Abreu (1993), ou seja, inclui apenas os metassedimentos de origem glacial (Formação Jequitaí e equivalentes) e os metassedimentos arenosos e conglomeráticos que ocorrem sob os metassedimentos glacigênicos e sobre unidades do Supergrupo Espinhaço. As litologias desse grupo afloram definindo uma estreita faixa ao longo da borda ocidental da SdEM e contornando, parcialmente, a Serra do Cabral (Fig.1). Expressiva distribuição areal de rochas desse grupo aparecem nas regiões de Jequitaí e a norte e nordeste da SdEM (Fig.1).

O Grupo Bambuí é dominado por sequências carbonáticas com intercalações de unidades pelíticas. Ocupa vasta área do Cráton do São Francisco inserindose às bordas ocidental e setentrional da SdEM onde recobre litologias ou do Grupo Macaúbas ou do Supergrupo Espinhaço.

\section{O RIFTE ESPINHAÇO}

\section{Generalidades}

As 3 formações inferiores do Supergrupo Espinhaço (formações Bandeirinha, São João da Chapada e Sopa-Brumadinho) indicam, claramente, através dos seus sistemas deposicionais e dos elementos estruturais da tectônica sin-extensional associada, que o Rifte Espinhaço evoluiu em 3 fases distintas. Embora essas 3 formações sejam unidades litoestratigráficas, as discordâncias, maiores ou menores, que as separam conferem também uma conotação cronoestratigráfica entre elas e isso é corroborado pelas datações geocronológicas.

O Rifte Espinhaço mostra claras evidências de que foi termalmente controlado e está de acordo com a crescente aceitação de que a causa maior da dinâmica continental provêm do fluxo de calor oriundo do manto (Burke \& Dewey 1973, Anderson 1982, Gurnis 1988, Maruyama 1994) e mesmo de toda e qualquer atividade tectônica conforme acentuado por Kumazawa \& Maruyama (1994: 86) The presence of temperature gradient is a necessary condition to keep the engine working by cooling at the top under gravity rather than by heating... The actual tectonics is determined by relevant non-stationary competition and balance between the release rate and storing rate of gravitational energy.

A evolução complexa e compartimentada do Rifte Espinhaço evidencia também semelhanças com os processos de extensão dos riftes fanerozóicos (sensu Illies 1981, Nelson et al. 1992, Wang \& Sun 1994) com forte influência da estruturação crustal prévia (sensu Bosworth 1985), embora mostre regimes sedimentares peculiares em função das condições climáticas específicas e da falta de cobertura vegetal terrestre que caracterizaram o Pré-cambriano.

\section{A Primeira Fase do Rifteamento}

Por volta de 1750 Ma vários domínios continentais sofreram processos de distensão crustal (Tankard et al. 1982, Southwick et al. 1986, Jackson et al. 1990), iniciando a fragmentação de um supercontinente amalgamado entre 2.100 e $1.800 \mathrm{Ma}$ (Barley \& Groves 1992 e referências por ele citadas). O início da extensão do Rifte Espinhaço mostra também idades semelhantes conforme datações obtidas por Machado et al. (1989, 1993) e Schobbenhaus et al. (1994) com valores entre 1752 e $1748 \mathrm{Ma}$.

$\mathrm{O}$ registro sedimentar/vulcânico dessa primeira fase de rifteamento acha-se preservado na porção mediana-central da SdEM e a nordeste dessa serra (região de Desembargador Otoni). Na primeira área mencionada é representado pelos metassedimentos da Formação Bandeirinha (ver litologias na Tab. 1) depositados em ambientes fluviais com contribuição eólica e de leques aluviais (Rodrigues da Silva 1995). A presença de red beds nessa unidade (Almeida Abreu 1993) caracteriza bem a idade de tais depósitos que, a exemplo de sedimentos continentais semelhantes da região norte-central dos Estados Unidos (Dott Jr. 1983) e da África do Sul (Tankard et al. 1982) foram depositados em torno de 1750 Ma. Por outro lado, evidenciam também a sombra climática causada pela existência de uma grande massa continental 
amalgamada nessa época, uma vez que, red beds são depósitos típicos de clima árido e semiárido (Parrish \& Barron 1986) e o clima global desse período da história da terra deve ter sido, em geral, intensamente quente e úmido (v. discussão em Almeida Abreu, 1993: 104-110).

Na região de Desembargador Otoni uma espessa sequência de rochas vulcânicas básicas é sobreposta por sedimentos de origem lacustre e fluvial (Chula et al. 1995) com intercalações locais de metariolitos que mostraram idades de $1752 \pm 2 \mathrm{Ma}$ (Machado et al. 1989). Essa região evidencia bem a forte atividade

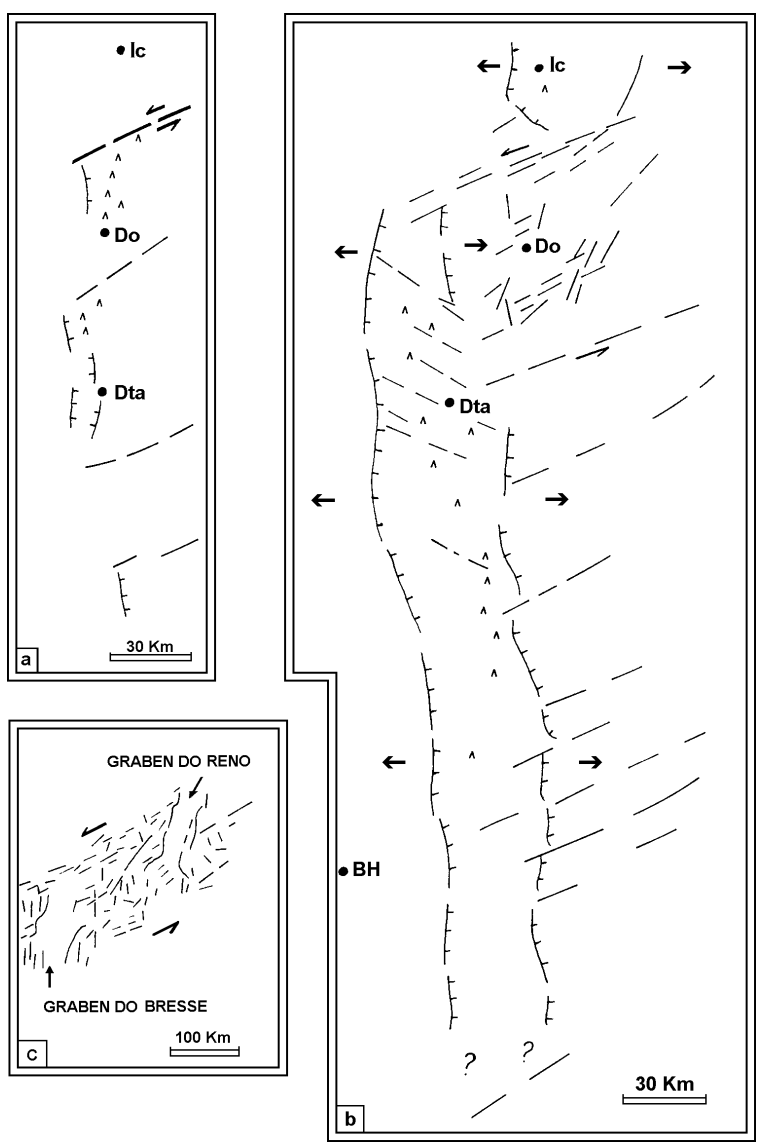

Figura 2: Propagação e segmentação do Rifte Espinhaço. a) Ilustra o desenvolvimento dos grabens da Formação Bandeirinha e unidades equivalentes.

b) Mostra a individualização dos segmentos setentrional e meridional durante a propagação do rifte, à semelhança da segmentação dos grabens do Reno e Bresse (Nelson et al. 1992) mostrada em c).

Simbologia: ${ }^{\wedge}$-vulcanismo basáltico ou riolítico associado à abertura do rifte; $\mathrm{BH}$ - Belo Horizonte; DO - Desembargador Otoni; Dta - Diamantina; Ic Itacambira.

Figure 2: Propagation and segmentation of Espinhaço Rift. a) shows the development of grabens of the Bandeirinha Formation and equivalent units. b) shows the individualization of the northern and southern segments during rift propagation similar to the segmentation of the Rhine and Bresse grabens (Nelson et al., 1992). Symbols: ^- basic and acid volcanism related to rift extension; $\mathrm{BH}$ - Belo Horizonte; DO - Desembargador Otoni; Dta Diamantina; Ic - Itacambira. vulcânica associada à extensão e propagação do Rifte Espinhaço e marca, também, o domínio de segmentação das partes meridional e setentrional do rifte (Fig. $2 a$ e $b$ ) através de um importante sistema de falhas de transferência de movimento transformante, determinando uma interação do tipo offset (sensu Nelson et al. 1992), a exemplo de muitos riftes Cenozóicos (Fig. 2 c).

A intensa atividade tectônica sin-extensional durante a sedimentação da Formação Bandeirinha é evidenciada pela profunda discordância angular e erosiva que a separa da Formação São João da Chapada sobrejacente. A extensão crustal foi acomodada por uma master fault (detachment) vergente para W, considerando que os blocos da Formação Bandeirinha foram basculhados para $\mathrm{E}$ (v. discussão em Almeida Abreu 1993: 79-82). As relações dessa formação com as rochas que lhe servem de embasamento mostram, por outro lado, que as falhas que acomodaram a deformação extensional foram exumadas trazendo à superfície rochas da crosta intermediária - os xistos do Grupo Costa Sena que junto com o Complexo Basal definem um core-complex sin-sedimentar no sentido de Coney (1980), Davis (1983), Spencer (1984) e Buck (1988). Não por acaso, portanto, na faixa mediana-central da SdEM ressalta-se um importante alto estrutural para as unidades do Grupo Guinda, que é o alto estrutural de Gouveia (Almeida Abreu 1989). Numa escala regional pode-se visualizar o Rifte Espinhaço, em termos de dinâmica crustal e atividade termal mantélica associada, na forma sumarizada na figura 3 .

\section{A Segunda Fase do Rifteamento}

Como acentuado anteriormente, a primeira fase do Rifte Espinhaço foi marcada por intensa atividade termal, evidenciada pelo forte vulcanismo, como também pelo arqueamento extensivo de blocos crustais. A tectônica quiescente subsequente, permitiu uma breve relaxação termal da crosta instalando-se então uma larga e extensa bacia fluvial onde foi depositada a Formação São João da Chapada. Na bacia onde instalou-se um sistema fluvial entrelaçado (Martins Neto, 1993) que caracteriza o ambiente desta formação, a atividade tectônica praticamente inexistiu. Os ciclos sedimentares dessa formação são depósitos de fluxo progradantes (de W para E - a predominância das paleocorrentes de todas as formações do Supergrupo Espinhaço da SdEM, especialmente das unidades da fase rifte, são de W para E, conforme Almeida Abreu 1993 e referências por ele citadas) alternados com depósitos agradacionais sugerindo, portanto, que os espaços de sedimentação e a evolução dessa bacia foram controlados por subsidência mecânica sob regime climático permanentemente úmido (esta última assertiva deduzida pela pureza dos sedimentos - predominantemente quartzo-arenitos pela ausência de red beds e pelo retrabalhamento eólico pouco expressivo e pela presença de paleolateritas/bauxitas que são representadas pelos filitos 

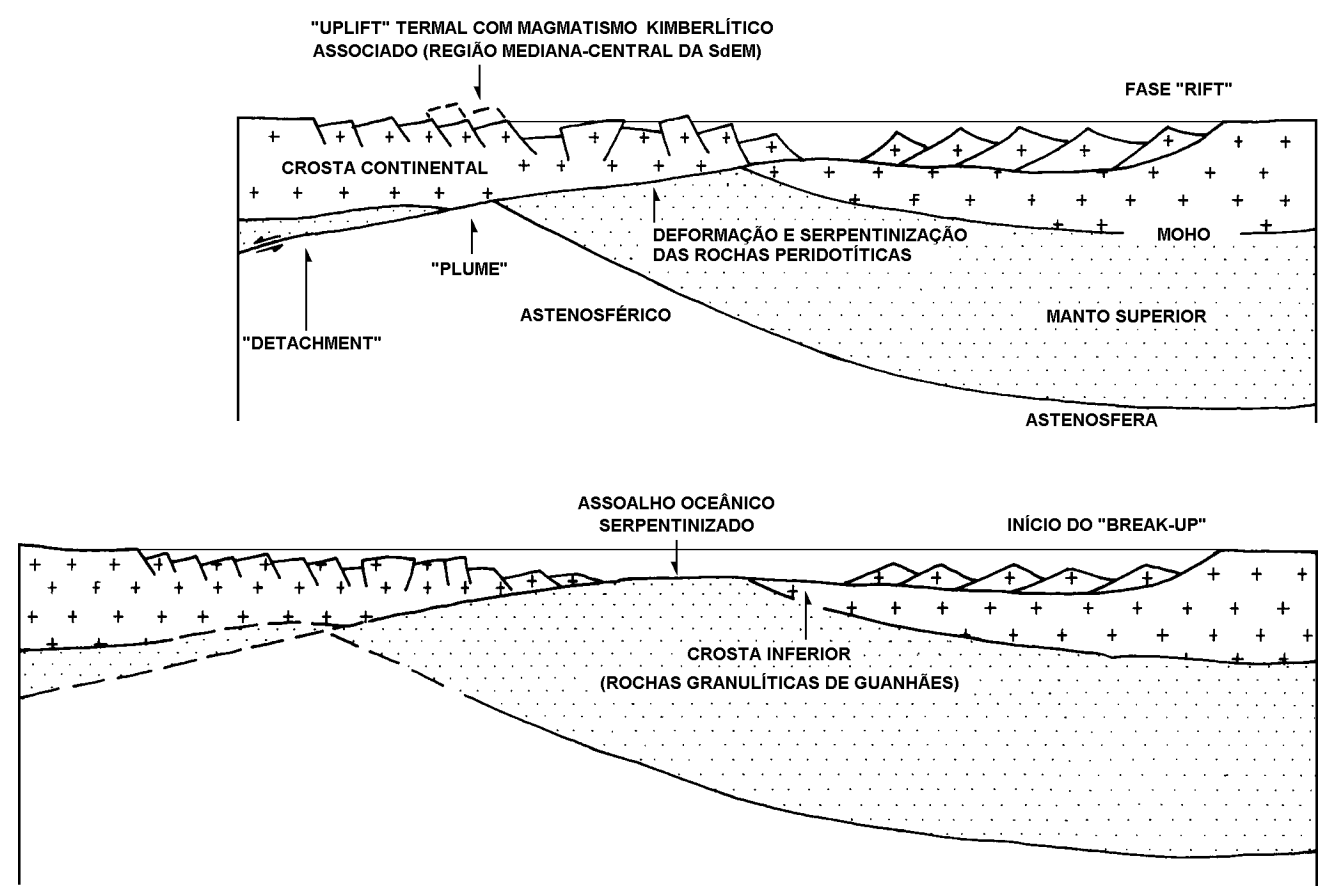

Figura 3: Evolução do Rifte Espinhaço segundo Almeida Abreu (1993), seguindo modelo de Lemoine et al. (1987).

Figure 3: Evolution of the Espinhaço rift after Almeida Abreu (1993) according to the model of Lamoine et al. (1987).

hematíticos).

Os depósitos rudíticos desta formação são, em termos de volume e extensão, negligenciáveis, concentrando-se quase que exclusivamente na parte mais basal e mesmo assim são pouco espessos e notavelmente descontínuos. Os depósitos maiores de ruditos ocorrem, invariavelmente, quando essa formação acha-se assentada diretamente sobre rochas da Formação Bandeirinha e são típicos fanglomerados (fluxo de detritos sem coesão) evidenciando o relevo proeminente desta última formação referida quando do início da sedimentação da Formação São João da Chapada.

Notável é que nas duas formações inferiores (Bandeirinha e São João da Chapada) os depósitos de lutitos são virtualmente ausentes predominando, conforme, referido anteriormente, metarenitos puros, em geral, quartzo-arenitos (v. Tab. 1). Sabe-se, através do espectro de minerais pesados (Schöll \& Turinsky 1980, Almeida Abreu 1993), que os sedimentos dessas formações são provenientes de rochas graníticas s.l. ressaltando, portanto, um pronunciado déficit no balanço de massa. Esses dados combinados evidenciam claramente: 1) acentuadas taxas de intemperismo, provavelmente em clima quente e úmido com elevadas pressões de $\mathrm{CO}_{2}$ atmosférico (Nesbitt \& Young 1984, Kasting 1989); 2) acentuada segregação nas bacias sedimentares, provavelmente devido a ausência de cobertura vegetal terrestre, com a remoção de partículas finas dos sistemas através das correntes fluviais e eólicas.

É certo que as seções preservadas (e conhecidas) da Formação Bandeirinha representam segmentos proximais e mediais de sistemas fluviais (Rodrigues da Silva 1995), assim como as da Formação São João da Chapada (Almeida Abreu 1993, Martins Neto, 1993). Os segmentos distais desses conjuntos - onde deveriam concentrar-se os lutitos - podem ter sido parcialmente reciclados ainda durante a fase rifte da Bacia Espinhaço em virtude da proeminente atividade extensional que provocou intensa movimentação de blocos crustais. A parte maior desses sedimentos, contudo, devem ter sido depositados na zona axial do rifte (em ambiente lacustre, de playa ou mesmo marinho) e esse domínio sofreu, particularmente, o efeito da tectônica compressiva considerando que situa-se na região proximal da colisão continental. Sendo assim, é difícil (senão impossível) diferenciar (do que ainda acha-se preservado) unidades dessas duas formações.

\section{A Terceira Fase do Rifteamento}

A terceira e última fase de extensão crustal do Rifte Espinhaço é marcada pela deposição das formações Sopa-Brumadinho e Galho do Miguel.

A retomada de extensão crustal parece, mais uma vez, associada ao forte aquecimento termal imposto à crosta continental que sustentou o Rifte Espinhaço. O ápice desse aquecimento deve ter ocorrido com a delaminação da litosfera que permitiu o acesso da astenosfera à base da crosta (Fig. 3). Esse postulado explica simultaneamente o extensivo vulcanismo kimberlítico - e/ou de rochas parentes - (denunciado pelos diamantes que ocorrem nos metaconglomerados da Formação Sopa-Brumadinho ao longo da faixa central da SdEM, desde o Campo de São Domingos 
até o Quadrilátero Ferrífero, por cerca de $250 \mathrm{Km}$ na direção N-S) e o forte uplift termal associado em conformidade com fenômenos descritos por Bird (1979 e referências por ele citadas) no sudoeste do EUA e em outras regiões.

Esse uplift é denunciado por: 1) a Formação São João da Chapada mostra espessuras de algumas centenas de metros na região do povoado homônimo e a norte e nordeste deste, como também espessuras superiores a $400 \mathrm{~m}$ na região de Extração, enquanto na região mediana-central é muito delgada ou ausente revelando, portanto, soerguimento crustal - antes e/ ou durante a sedimentação da Formação Sopa- pelíticas e areníticas, desta formação (ver discussão em Almeida Abreu 1993).

O foco da deformação extensional progradou sucessivamente para leste em consequência de: 1) a zona submetida à movimentação crustal sofre profunda rotação de blocos e, por consequência, diminuição do ângulo das falhas normais e impedindo, portanto, a continuidade de seus movimentos; 2) a crosta sofrendo extensão move-se e afasta-se progressivamente do foco termal; 3) a rotação do meio-graben se processa em torno de um eixo horizontal resultando no soerguimento lento e progressivo da sua margem oposta mais estável (em relação à borda de maior

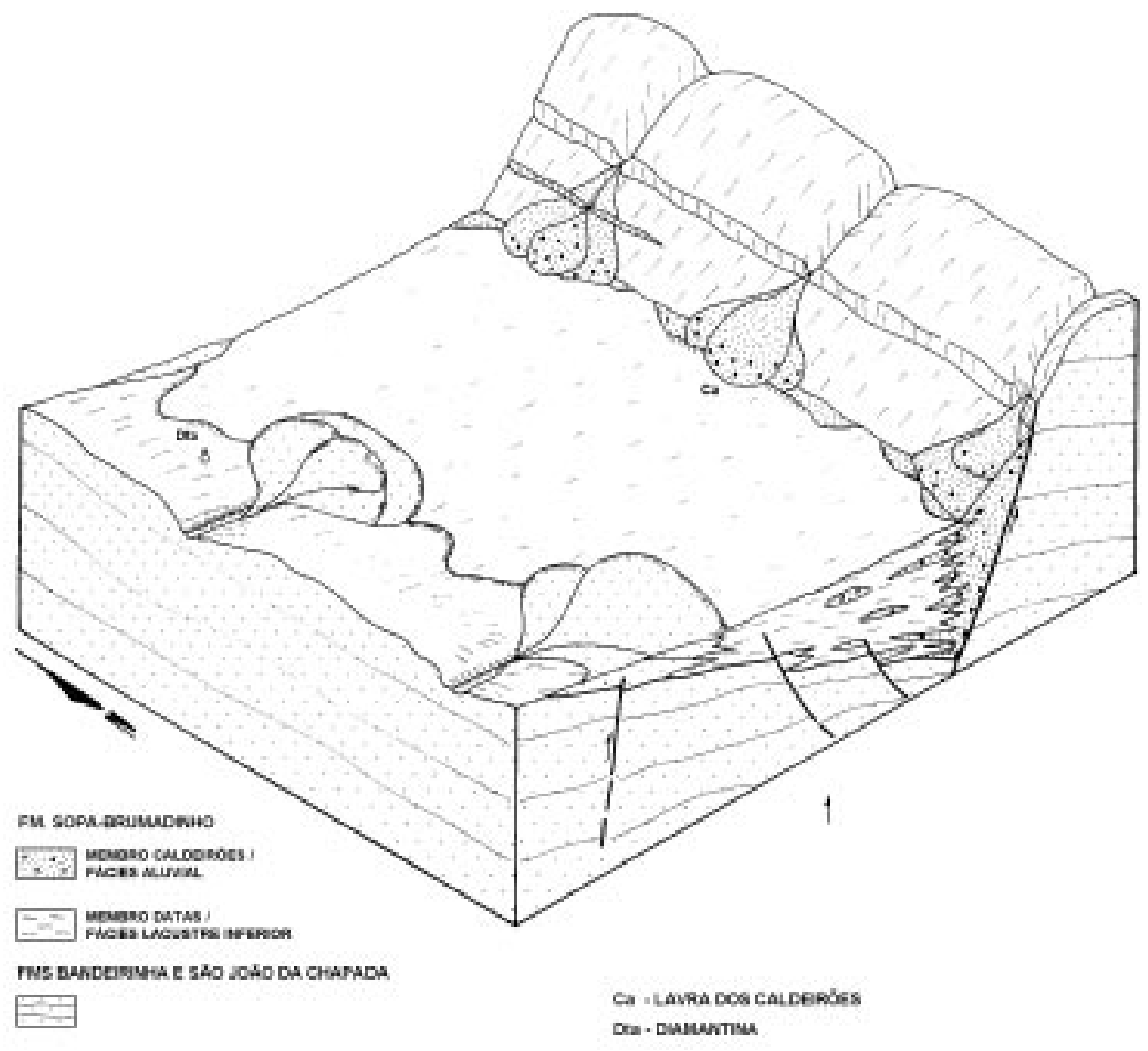

Figura 4: Bloco-diagrama esquemático (não em escala) da calha lacustre desenvolvida durante a deposição da Formação Sopa-Brumadinho na região de Diamantina-Sopa-Caldeirões.

Figure 4: Schematic block-diagram (not to scale) of the lacustrine trough developed during deposition of the Sopa-Brumadinho Formation in the Diamantina-Sopa-Caldeirões.

Brumadinho - de no mínimo $400 \mathrm{~m}$; 2) ao longo da faixa mediana-central da SdEM instalou-se um sistema de meio-grabens alinhados na direção N-S, embora segmentados por falhas de transferência, conformando calhas lacustres (Fig. 4) com leques aluviais progradantes de $\mathrm{W}$ para $\mathrm{E}$ (os ambientes lacustres da Formação Sopa-Brumadinho foram reconhecidos inicialmente por Almeida Abreu \& Pflug 1992, 1994; Almeida Abreu 1993 e, posteriormente, por Martins Neto 1993).

A atividade crustal nesse período foi intensa conforme revelado pelos espessos e extensivos depósitos de ruditos da Formação Sopa-Brumadinho e por suas complexas relações com as fácies lacustres, atividade tectônica e, por consequência, de maior aporte sedimentar - Fig. 5), determinando assim a formação de falhas de alto ângulo (dormant faults) que podem absorver melhor a deformação e criando, portanto, um novo meio-graben adjacente.

Isso é observado na SdEM desde a sua faixa mediana-central (Presidente Kubitscheck-Datas-SopaSão João da Chapada) até sua borda oriental (Itapanhoacanga-Serra do Itambé), onde 3 sistemas de meio-grabens longitudinais $(\mathrm{N}-\mathrm{S})$ propagaram-se sucessivamente de $\mathrm{W}$ para $\mathrm{E}$. A medida que a deformação migrou para formar o meio-graben oriental adjacente, as calhas abandonadas pela deformação foram sendo progressivamente assoreadas 

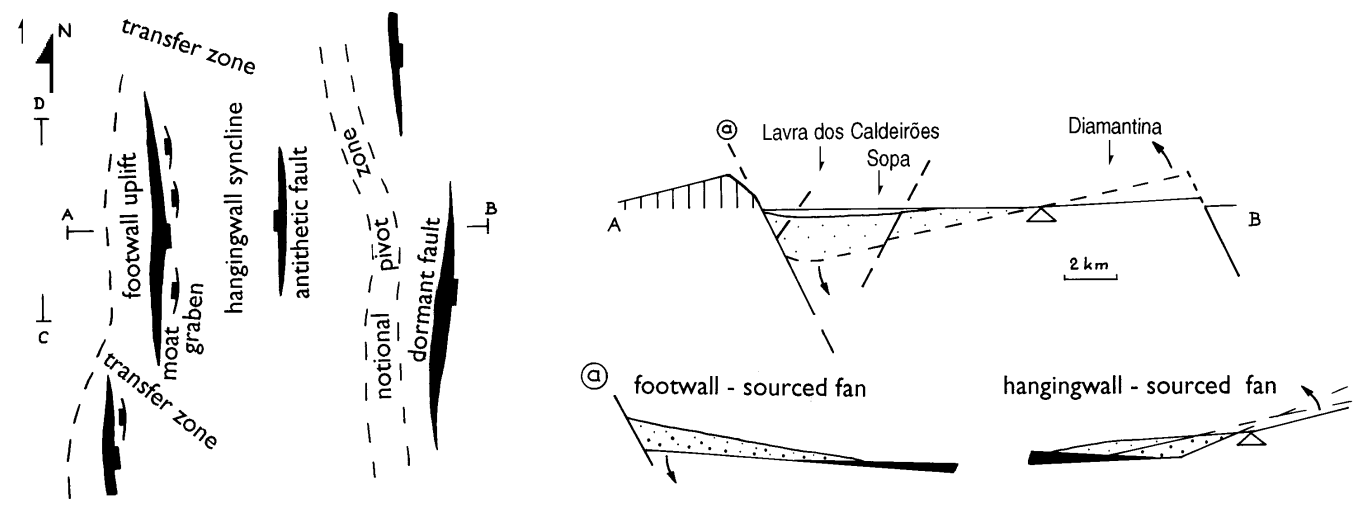

Figure 5: Principais elementos morfológicos e estruturais de bacias extensionais (segundo Leeder et al. 1988). Note a transferência do locus de sedimentação para uma calha adjacente devido a rotação progressiva do meiograben ativo.

Figure 5: Main morphologic and structural elements of the extensional basins (after Leeder et al. 1988). Note the transfer of the sedimentation locus to the adjacent trough due to the progressive rotation of the active half-graben.

pelas fácies eólicas da Formação Galho do Miguel (ver nas tabelas 1 e 2 as litologias e fácies sedimentares das formações Sopa-Brumadinho e Galho do Miguel; descrições detalhadas destas podem ser obtidas em Almeida Abreu 1993 e Almeida Abreu \& Pflug 1994).

O início da extensão crustal do Rifte Espinhaço, conforme mencionado anteriormente, ocorreu por volta de $1750 \mathrm{Ma}$, enquanto a terceira fase de rifteamento deve ter iniciado entre 1711 e $1700 \mathrm{Ma}$ de acordo com as datações de metariolitos que ocorrem intercalados nos metassedimentos das formações São João da Chapada e Sopa-Brumadinho na borda sudeste da SdEM (Machado et al. 1989) e de filitos hematíticos que afloram na faixa mediana- central dessa serra (Dossin et al. 1993). A fragmentação continental dos riftes/bacias termalmente controladas sucede-se após um período de 50 a 100 milhões de anos de extensão crustal (Royden et al. 1980, Houseman \& England 1986) o que projeta o final da terceira fase de rifteamento do Rifte Espinhaço para cerca de $1650 \mathrm{Ma}$.

$\mathrm{Na}$ região de Itapanhoacanga, o terceiro sistema de meio-grabens dessa fase de rifteamento mostra-se preenchido por um fan-delta onde as fácies fluviais (arenitos e ruditos) da Formação Sopa-Brumadinho progradaram a calha lagunar que é representada por BIF's e pelitos da Sequência Itapanhoacanga (Fig. 6). Reportando-se mais uma vez ao modelo da Figura 3

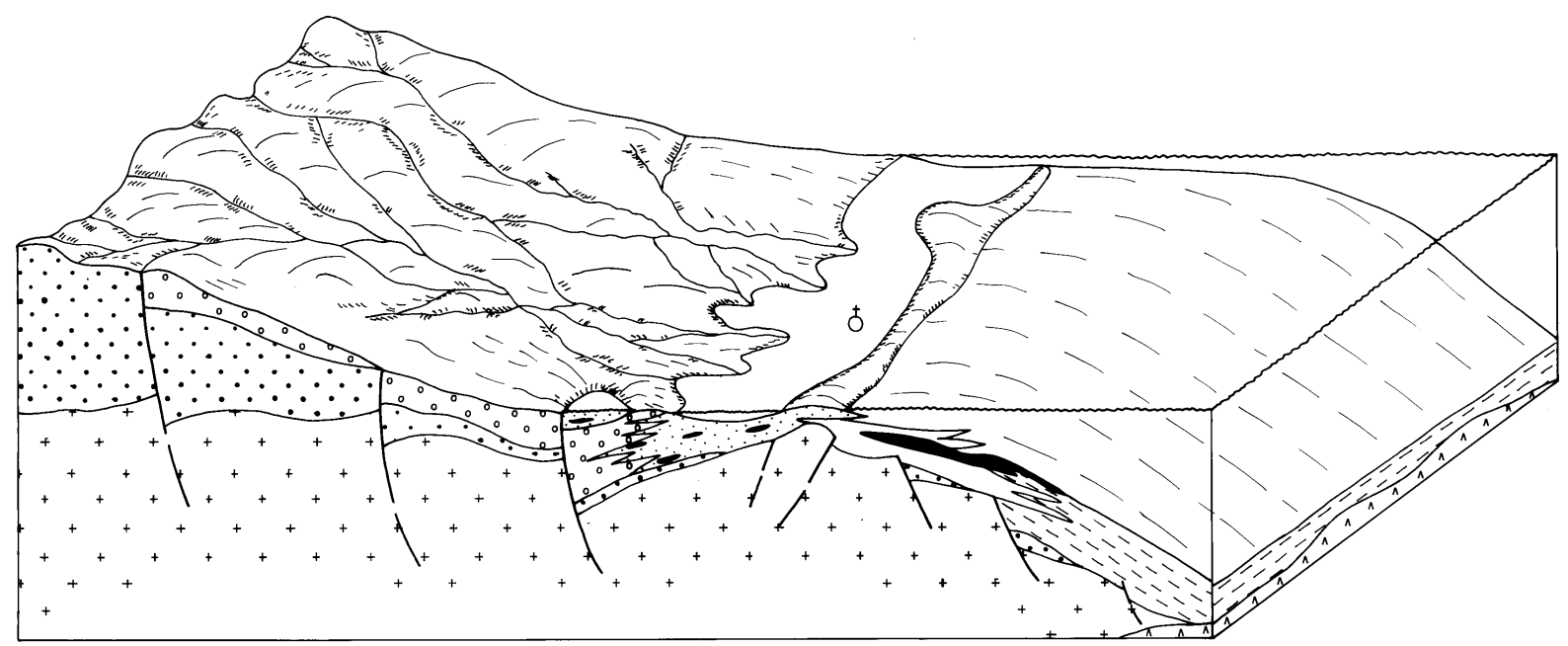

${ }_{0}^{\circ}$ FM. SOPA-BRUMADINHO : FAN-DELTA COMPLEXO

$\because$ SEDIMENTOS E VULCĀNICAS DO RIFT: FMS BANDEIRINHa,

Sẫo joÃo da CHAPADA E SOPA-BRUMADINHO.

++ COMPLEXo BASAL

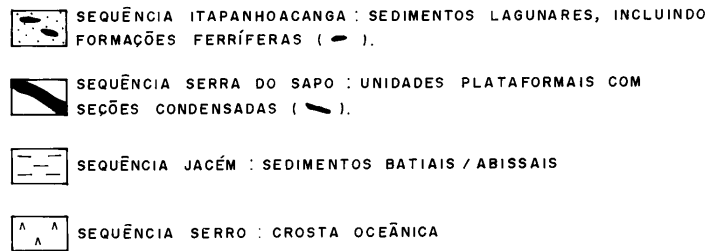

† itAPANHOAganga

${ }_{n}^{n}$ SEQUênCIA SERRo: CRosta OCEĀNICA

Figura 6: Bloco-diagrama esquemático (não em escala) mostrando a progradação do fan-delta da Formação SopaBrumadinho na calha lagunar da Sequência Itapanhoacanga (Almeida Abreu 1993). Observe que os processos de rifteamento foram ativos até o início da instalação da bacia marinha/oceânica (compare com as figuras 3 e 7).

Figure 6: Schematic block-diagram (not to scale) showing the fandelta progradation of the Sopa-Brumadinho

Formation onto the lagunar trough of the Itapanhaoca Sequence (Almeida Abreu 1993). The rifting processes were until the marine/oceanic basin instalation. 
admite-se, que nessa fase de evolução do Rifte Espinhaço, o manto litosférico foi exposto à superfície determinando a instalação de uma bacia marinhaoceânica (compare as figuras 3 e 6).

A crosta continental atenuada e segmentada pelas falhas normais e de transferência que acomodam a extensão crustal (em fases precedentes ou durante o ataque final da fragmentação continental) sujeita-se a intrusões de diápiros serpentiníticos que são, em última análise, rochas mantélicas fortemente hidratadas (Boillot et al. 1989).

Ao longo da borda leste da SdEM faixas e corpos de rochas ultramáficas, mais ou menos serpentinizadas (e metamorfisadas), ocorrem imbricadas tectonicamente com metassedimentos do rifte e de unidades marinhas do Sistema Espinhaço e com o embasamento cristalino (Fig. 7 e 9). A foliação principal dessas rochas, ao contrário das demais entidades tectônicas do thrust belt que limita a borda oriental da SdEM, mostram, invariavelmente, alto ângulo. Além disso, as variações composicionais dessas rochas evidenciam claramente diferenciações sofridas durante o emplacement das mesmas (A. de C. Zapparoli, em preparação). A composição, estruturação e a relação dessas rochas com as unidades do Sistema Espinhaço evidenciam que as mesmas representam diápiros mantélicos que ascenderam na zona axial do Rifte Espinhaço no início da fragmentação continental, a exemplo do que ocorreu no Atlântico Norte - costa da Galícia - (Boillot et al. 1989), na costa sudoeste da Austrália (Nicholls et al. 1991) e no Ligurian Tethys - Mesozóico Alpino - (Lemoine et al. 1987).

\section{A BACIA}

É difícil saber se uma bacia (ou bacias) marinhas desenvolveram-se em etapas mais precoces da fase rifte do Sistema Espinhaço mas, se assim, aparentemente não tiveram conexão com as calhas do rifte até o início da fragmentação continental. No início do breakup, entretanto, a instalação de uma bacia marinha é claramente denunciada pelos depósitos das Sequências Itapanhoacanga, Serra do Sapo e Jacém (Fig. 6), que conviveu com o final da distensão das partes distais do rifte, a exemplo de margens passivas meso-cenozóicas (Boillot et al. 1989).

Uma vez o manto litosférico é exposto à superfície - desenvolvendo, portanto, uma crosta oceânica - os processos de rifteamento fenecem quase que automaticamente devido a menor capacidade de transmissão de calor da crosta continental e também em função da célula de convecção criada com o advento da crosta oceânica que passa a ser o foco de fuga e difusão de calor e também a zona de spreading com a constante geração de nova crosta.

Assim, a crosta continental aquecida durante a fase de rifteamento é submetida a uma pronunciada

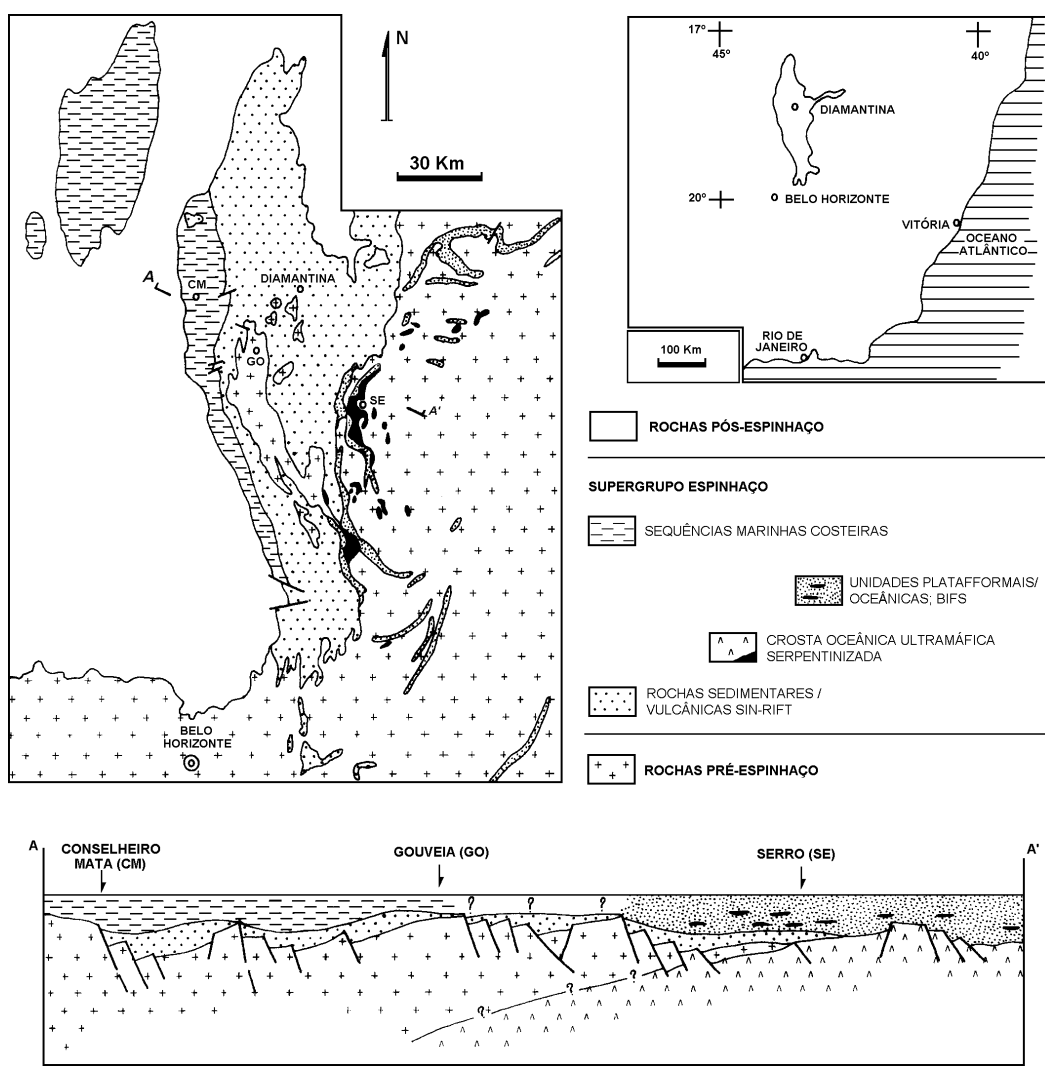

Figura 7: Seção esquemática (segundo Almeida Abreu 1993) mostrando a Bacia Espinhaço no tempo do desenvolvimento da sua margem continental passiva. Note que na região mais atenuada da crosta continental aparecem diápiros mantélicos (compare com a figura 3). O mapa (parte superioresquerda da figura) localiza a seção e mostra a distribuição atual das unidades litoestratigráficas maiores da SdEM.

Figure 7: Schematic cross-sesction (after Almeida Abreu 1993) showing the Espinhaço basin at the continental passive margin times. Note the diapiric emplacement of mantle material in the atenuated continental crust (compare with Fig.

3). The map (left-upper part of figure) localizes the cross-section and shows the present distribution of the major litostratigrafic units of the SdEM. 
subsidência (por relaxação termal), quando o fluxo de calor passa a ser difundido pela crosta oceânica recémcriada. Note-se que o domínio costeiro da bacia marinha Espinhaço instalou-se na região de Itapanhoacanga (linha sub-meridional da cidade de Serro - Fig. 7) e após a contração termal da bacia ocorreu uma pronunciada transgressão marinha levando a zona costeira da margem passiva Espinhaço para os domínios ocidentais da atual SdEM (Fig. 7), ou seja, esta foi transferida cerca de $80 \mathrm{~km}$ para oeste (sem considerar o encurtamento crustal a que foi submetido o Orógeno Espinhaço).

As formações do Grupo Conselheiro Mata representam as sequências marinhas costeiras e plataformais (em parte) da margem passiva Espinhaço. Esse grupo reúne um espesso pacote de sedimentos clásticos (alternâncias de pelitos e arenitos - ver Tab. 1), localmente com lentes de dolomitos.

Notável é que as cinco formações desse grupo mostram contatos normais e, em geral, gradacionais entre si, evidenciando que representaram ambientes sedimentares contíguos (Köster 1984) configurando um clássico exemplo do princípio de fácies da Lei de Walther. Fato intrigante é a persistente homogeneidade lateral das fácies dessas unidades, especialmente das formações Santa Rita e Córrego dos Borges, que estendem-se, sem nenhuma variação faciológica significativa, por cerca de $160 \mathrm{Km}$ ao longo da borda ocidental da SdEM e isso vem indicar que: 1) os ambientes foram uniformes e, sobretudo, estacionários; 2) a inexistência de rios caudalosos desembocando na costa dessa bacia marinha, considerando que essas unidades são de ambientes costeiros a plataformais.

Tudo isso vem reforçar o caráter especial dos sistemas fluviais pré-cambrianos, em face da ausência de cobertura vegetal terrestre que inibiu o desenvolvimento de canais confinados (Schumm 1968) impondo, sistematicamente, a formação de sistemas de canais entrelaçados. Mas, por outro lado, a ausência de cobertura vegetal leva a um significativo aumento do run-off o que, por consequência, deve levar ao aumento das taxas de sedimentação nas bacias com psefitos, psamitos e/ou pelitos de acordo com o relevo e com a curva hipsográfica. Como já foi dito, o registro existente mostra que as taxas de sedimentação foram constantes sobre uma plataforma estável e com contribuições fluviais discretas (Köster 1984, Almeida Abreu 1993).

Esse quadro vem demonstrar que o Précambriano conviveu com outras situações também específicas e, ao que parece, em decorrência dos parâmetros termais da sua litosfera que seriam algo mais aquecidas em relação aos padrões fanerozóicos (Burke \& Ashwal 1990, Hynes 1982). Se assim, alterações no continental freeboard devem ser esperadas (Galer 1991) influenciando fortemente a curva hipsométrica que, aliada às características climáticas vigentes, influenciariam significativamente na curva hipsográfica. Moores (1993) baseado no registro de espessuras de crostas oceânicas précambrianas (pré - $1.0 \mathrm{Ga}$ ), sugere que mais de $90 \%$ das áreas continentais estavam inundadas (abaixo do nível do mar) durante o Mesoproterozóico.

Assim, visualiza-se que a plataforma que recebeu os sedimentos da margem passiva Espinhaço era muito plana e estável e que as áreas continentais emersas ocupavam uma superfície areal bem menor do que os padrões de continental freeboard fanerozóicos e com relevo suave e uniforme. Isso, contudo, não impediu que ocorressem oscilações significativas do nível do mar, como as registradas nas unidades do Grupo Conselheiro Mata (ver discussão em Almeida Abreu 1993: 102-103) que podem ter sido motivadas pelos processos clássicos causadores de tais fenômenos como, variação no volume de cadeias oceânicas e variações do stress nas placas litosféricas (Cathles \& Hallam 1991).

Deve ser destacado que as litologias reunidas no Grupo Conselheiro Mata representam apenas uma parte do prisma sedimentar da plataforma continental da margem passiva Espinhaço. Somas significativas de sedimentos devem ter sido erodidas antes e durante a sedimentação do Grupo Macaúbas incluindo, provavelmente, litologias de uma plataforma carbonática, uma vez que, nos meta-tilitos deste grupo (Formação Jequitaí) aparecem muito carbonato sob a forma de clastos ou matriz e esse material foi proveniente da área montanhosa definida pelo sistema Espinhaço nesse período.

\section{O ORÓGENO}

A tafrogênese imposta à crosta evolui de diferentes maneiras levando, em geral, a formação de uma bacia intracratônica ou de uma margem continental passiva. A inversão tectônica das bacias é, por outro lado, um fenômeno que ocorrerá posteriormente, seja por transmissão da deformação através da crosta relacionada aos ciclos orogenéticos maiores - seja pela colisão de placas litosféricas como a consequência do colapso da crosta oceânica da bacia. Mesmo as bacias geradas por arqueamento flexural (p. ex. a Michigan basin - Howell \& van der Pluijm 1990) sujeitam-se a ambos os processos: tafrogênese e inversão tectônica.

A rigidez da crosta e da litosfera é um elemento finito e, portanto, limitada a um determinado volume de extensão e estiramento crustal. Uma vez esse limite é alcançado, a crosta continental é automaticamente fragmentada. Sendo assim, não é possível que um determinado segmento crustal seja submetido a um processo de distensão, mais ou menos contínuo, por centenas de milhões de anos sem que ocorra a sua fragmentação. Para o sistema litosférico do Fanerozóico esse limite de tempo não atinge 100 milhões de anos (Houseman \& England 1986).

A tafrogênese da Bacia Espinhaço teve início por 
volta de $1750 \mathrm{Ma}$, conforme referido anteriormente. Ao que tudo indica, esta foi submetida a um processo semi-contínuo de extensão crustal que, admitindo-se um menor vigor da crosta pré-cambriana em vista do sistema termal mais aquecido de sua litosfera (permitindo, portanto, um maior grau de estiramento), pode-se estimar que a fragmentação continental do Rifte Espinhaço ocorreu por volta de $1650 \mathrm{Ma}$.

Sob o ponto de vista teórico essa idade é bastante coerente em relação ao início da inversão tectônica da Bacia Espinhaço, estimada em 1.500 Ma, conforme datações geocronológicas em Lagoa Real (Sistema Espinhaço da Bahia, Cordani et al. 1992 e referências por eles citadas). Essa reportada coerência decorre da modelagem numérica efetuada por Hynes (1982), considerando o sistema litosférico pré-cambriano $100^{\circ} \mathrm{C}$ mais quente em relação aos valores atuais, que revelou um período máximo de estabilidade da crosta oceânica pré-cambriana da ordem de 140 milhões de anos.

Muitas outras idades entre 1400 e $1100 \mathrm{Ma}$ registram eventos metamórficos em rochas de origem ígnea e sedimentar de diferentes regiões da Serra do Espinhaço (Teixeira et al. 1990, Cordani et al. 1992, e referências citadas nesses artigos) revelando, em princípio, que a Orogênese Espinhaço perdurou por cerca de 2 a 3 dezenas de milhões de anos. Traços de fissão em muscovita de rocha do Complexo Basal da região de Itacambira revelaram idade da ordem de 1180 $\pm 90 \mathrm{Ma}$ indicando que esse complexo manteve-se fora
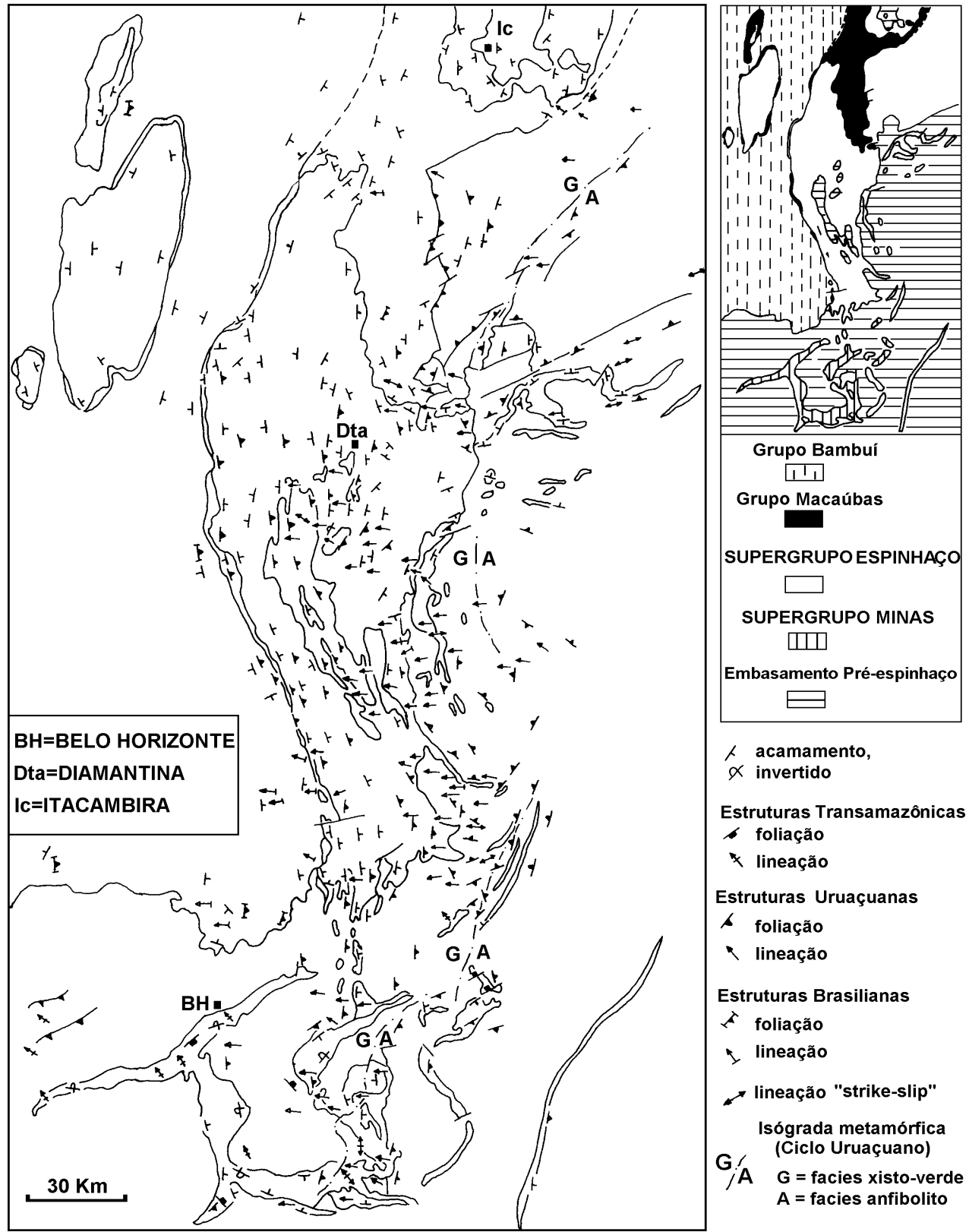

Figura 8: Trends estruturais e vergências relacionadas aos ciclos tectônicos proterozóicos. Lineações indicam o sentido do transporte tectônico. Para a fonte dos dados da figura, consultar Almeida Abreu \& Pflug (1994). Figure 8: Structural Trends and vergences related to the Proterozoic tectonic cycles. Lineation indicate the tectonic transport sense. For data source of figure see Almeida Abreu \& Pflug (1994). 


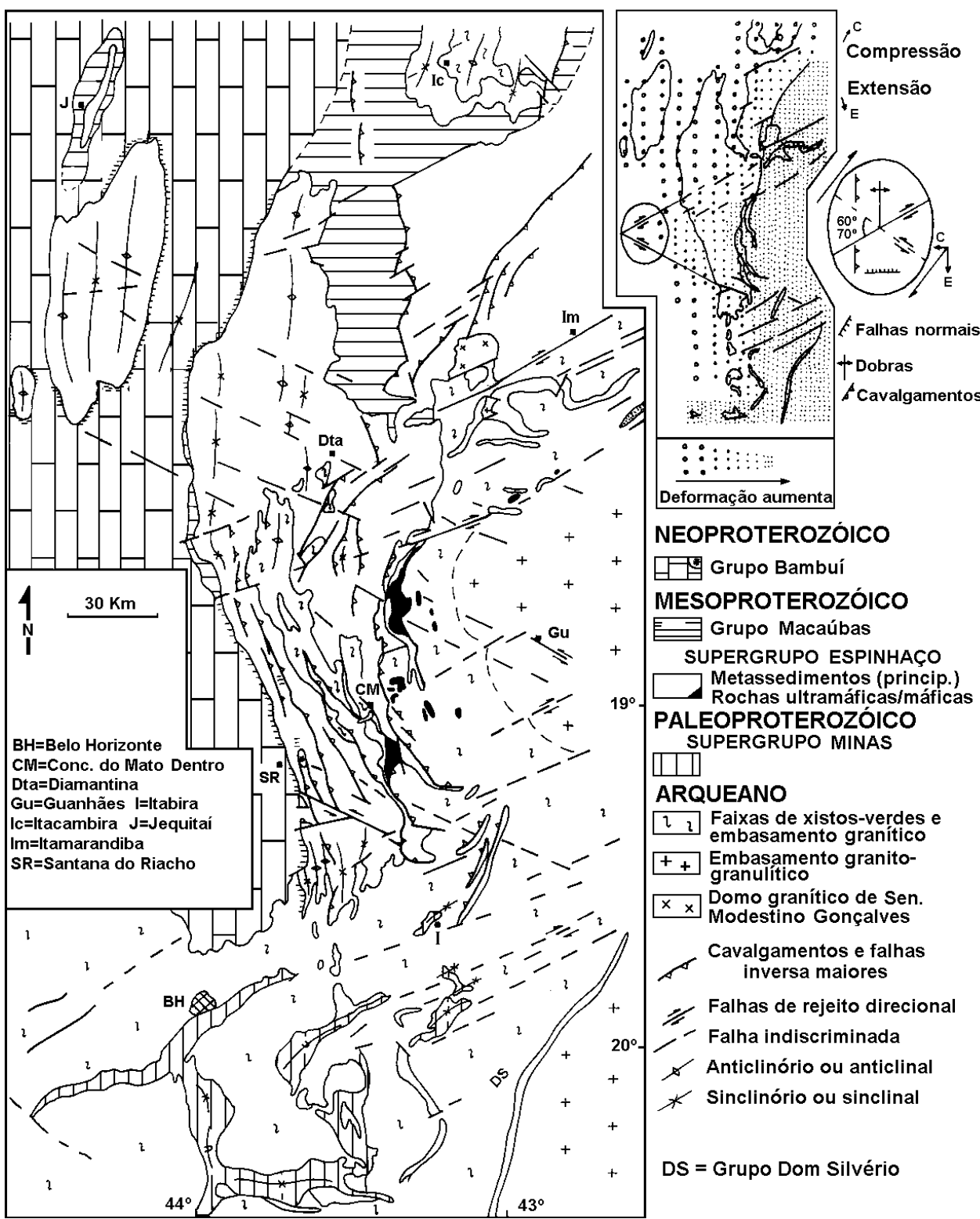

Figure 9: Elementos estruturais maiores da SdEM (segundo Almeida Abreu \& Pflug 1994). A tectônica em wrenching (figura do lado direito-superior: interpretação no sentido de Harding 1974), aliada a indentation das placas litosféricas opostas, foi responsável pela conspícua compartimentação da deformação (compare com a figura 10).

Figure 9: Major structural elements of the SdEM (after Almeida Abreu \& Pflug 1994). The wrenching tectonic (upper right corner: interpretation sensu Harding 1974), together the opposite lithospheric plate indentation was reponsible by the remarkable partitioned deformation (compare Fig. 10).

de qualquer sistema metamórfico a partir desse período (Siga Jr. et al. 1987).

Assim, a Serra do Espinhaço foi edificada ainda no Mesoproterozóico e mostra arranjo e feições típicas de um orógeno de colisão: 1) a deformação e o metamorfismo crescem da faixa externa para a zona interna (Fig. 8 e 9), a exemplo de outras faixas orogenéticas (Thompson \& England 1984); 2) a lineação de estiramento mineral é perpendicular às estruturas tectônicas maiores (falhas e dobras de 1a., 2a. e 3a. ordens) que definem o trend longitudinal N$\mathrm{S}$ da faixa orogenética (Fig. 8 e 9); 3 ) na zona interna (borda oriental da SdEM, Fig. 9) desenvolveu-se uma faixa de cavalgamentos alinhado ao trend do orógeno e coincidindo com a região de pronunciado espessamento crustal (Blitzkow et al. 1979).

A geometria e feições tectônicas do Orógeno Espinhaço, ou seja, trend $\mathrm{N}-\mathrm{S}$, transporte de massa para W e lineação de estiramento sobre os planos de foliação caindo para $E$, indicam que a subducção da crosta oceânica da bacia durante a inversão tectônica mergulhou para E (sensu Shackleton \& Ries 1984).

A terminação sul da Serra do Espinhaço Setentrional (região de Itacambira - Fig. 1) é representada por rochas quartzíticas de baixo grau metamórfico e são unidades equivalentes às formações do Grupo Guinda da SdEM e, portanto, sequências de origem fluvial e eólica (ver discussão em Almeida Abreu 1993: 85-86; 98-99). Considerando que a leste desse segmento da Serra do Espinhaço afloram extensivamente sequências marinhas costeiras e 
oceânicas pertencentes à Faixa Araçuaí e que o metamorfismo barroviano cresce para leste até a fácies anfibolito médio a alto (Pedrosa-Soares et al. 1992) configura, a exemplo do segmento meridional dessa serra, um perfil clássico de orógeno de colisão, ou seja, o metamorfismo e a deformação crescem da zona externa (W) para a zona interna (E) do orógeno. Sendo assim, e em vista da inexistência de discordâncias significativas entre um e outro conjunto, considerase a parte supracrustal da Faixa Araçuaí como as sequências da fase pós-contração termal da Bacia Espinhaço, do segmento setentrional da serra homônima.

Notável também na SdEM é a particular compartimentação da deformação. Como já foi dito, a exemplo de outros orógenos, a deformação das unidades do Supergrupo Espinhaço na SdEM cresce de $\mathrm{W}$ para $\mathrm{E}$ mas, também, mostra compartimentos de diferentes intensidades de deformação ao longo do seu com o trend meridiano das rochas ofiolíticas que acham-se imbricadas na faixa de cavalgamentos da borda oriental da SdEM, o que levou a propagação da deformação até as regiões externas do orógeno. Fora desses domínios (partes norte e sul da SdEM - Fig. 9), a deformação foi acomodada - durante a colisão continental - pelas grandes falhas de rejeito direcional. O controle exercido pelas body forces (sensu Platt et al. 1989) durante o ajuste das placas no processo de colisão está bem exaltado a norte de Itabira (Fig. 9 e 10) onde unidades da faixa de cavalgamentos foram rotacionadas cerca de $130^{\circ}$ no sentido anti-horário.

Os compartimentos menos deformados são dominados principalmente por dobras abertas, ligeiramente assimétricas e com vergência para $\mathrm{W}$ e, eventualmente, com falhas inversas de alto ângulo, muitas vezes rompendo os flancos ou charneiras das dobras. Nos compartimentos mais deformados as
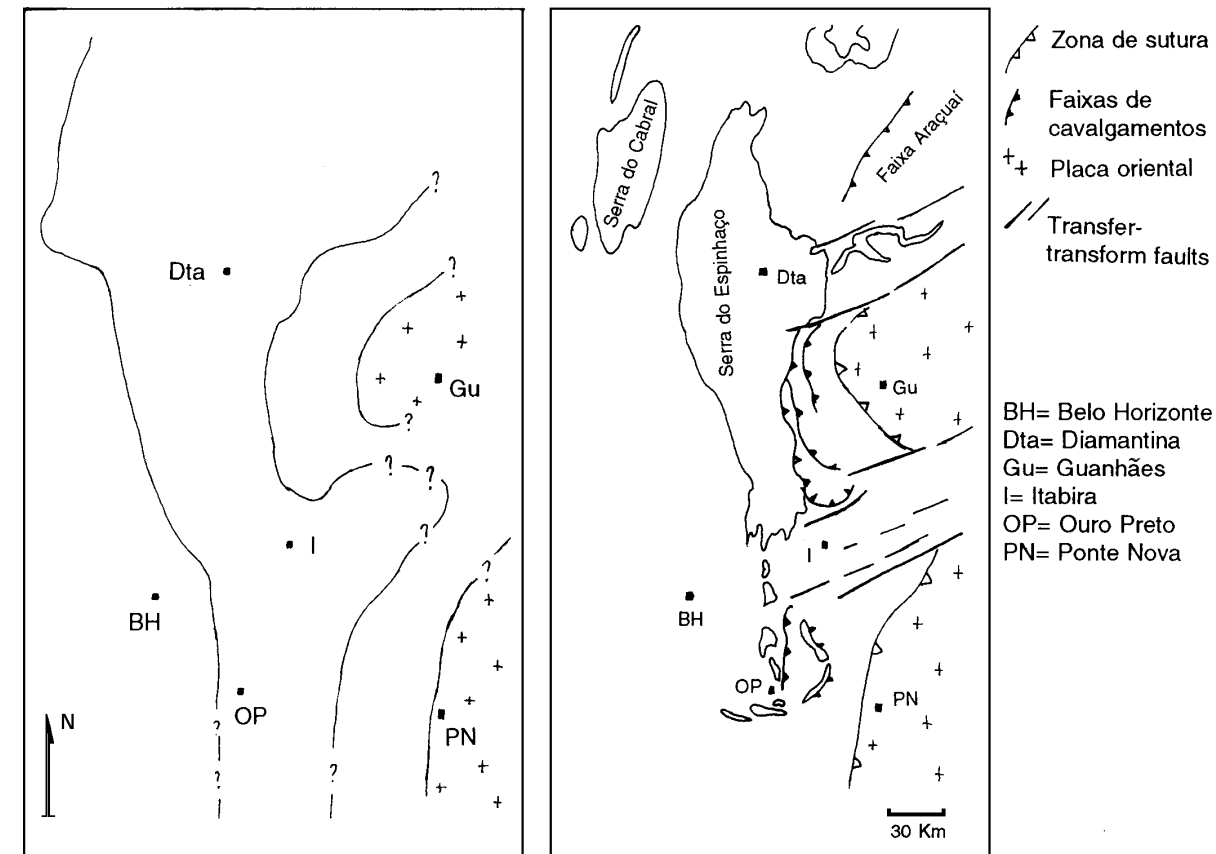

Figura 10: Mapa esquemático (segundo Almeida Abreu 1993) mostrando o arranjo das placas tectônicas durante a abertura da Bacia Espinhaço e os efeitos de suas geometrias na compartimentação da deformação e na organização estrutural durante a fase de colisão continental. Note o pronunciado promontório da placa ocidental a nordeste de Itabira.

Figure 10: Schematic map (after Almeida Abreu 1993) showing the tectonic plate arrangement during Espinhaço basin opening and their effects to the partitioning of deformation and to structural organization during the continental collision phase. Note the remarkable promontory of the western plate to the northeast of Itabira.

eixo longitudinal (Fig. 9) e isto é também uma feição de outras faixas orogenéticas como, por exemplo, nas Sierras Australes da Argentina (Cobbold et al. 1991) e nos Alpes ocidentais (Vialon et al. 1989).

Essa compartimentação longitudinal foi consequência do ajuste das placas litosféricas opostas durante o processo de colisão, em vista de seus contornos irregulares (Fig. 10), aliada aos movimentos direcionais das grandes falhas transcorrentes. Notese nas figuras 9 e 10 que os dois domínios onde as unidades exibem elevado strain (região centro-sul da SdEM e leste do Quadrilátero Ferrífero), ocorreu um choque frontal entre as placas opostas, coincidindo falhas de alto e baixo ângulos são dominantes, localmente preservando parte de dobras que foram transpostas pelas falhas (Fig. 11).

Isso indica claramente que os falhamentos são tardios em relação aos dobramentos, evidenciando que estes foram gerados nas fases iniciais da inversão tectônica e que os falhamentos foram desenvolvidos como a consequência da colisão continental.

Conforme mencionado anteriormente, é provável que todo o processo de orogênese da SdEM tenha ocorrido entre 1500 e $1200 \mathrm{Ma}$. Isso é corroborado pela presença dos depósitos glaciais da Formação 


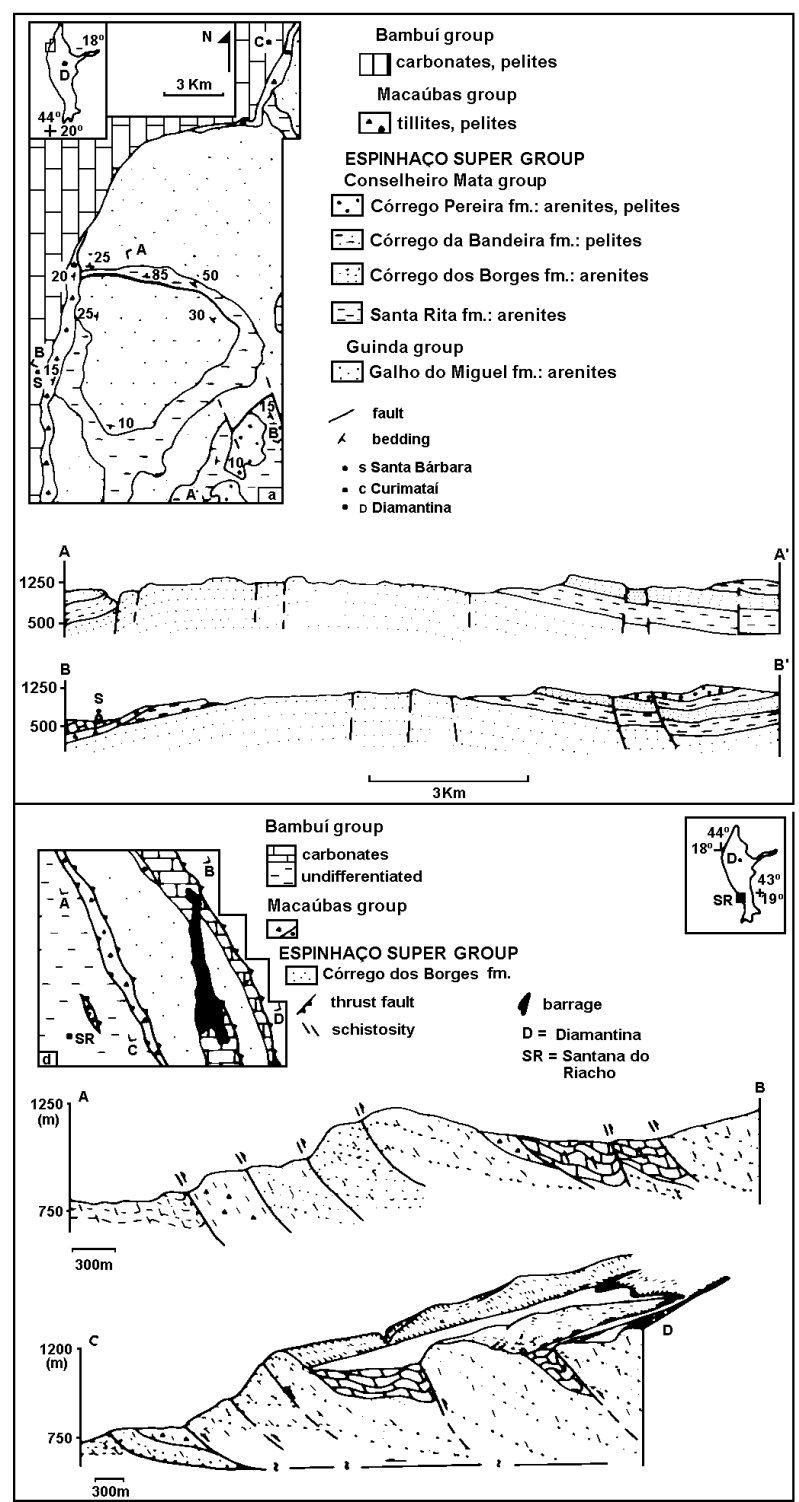

Jequitaí (Grupo Macaúbas e equivalentes) que bordejam sistematicamente as faixas mesoproterozóicas que circundam o Craton do São Francisco revelando-se, portanto, como um fenômeno glacial do tipo Alpino (glaciação de montanhas). Como pode ser visto na Figura 11, ressalta-se uma profunda discordância angular e erosiva entre as unidades do Grupo Macaúbas e do Supergrupo Espinhaço. Essa discordância torna-se ainda mais evidente quando é feito um perfil W-E na parte norte da SdEM, ou um perfil N-S ao longo da borda ocidental dessa serra: se no noroeste da SdEM (Fig. 11) os metatilitos do Grupo Macaúbas recobrem unidades do Grupo Conselheiro Mata (formações Santa Rita, Córrego dos Borges e Córrego da Bandeira), no nordeste e sudoeste dessa mesma entidade orográfica (e aproximadamente na mesma cota altimétrica), os metatilitos em questão recobrem rochas das formações São João da Chapada e Sopa-Brumadinho indicando, portanto, que a SdEM foi deformada, soerguida e profundamente erodida (provavelmente com a remoção de mais de 5.000 metros de metassedimentos) antes da deposição das

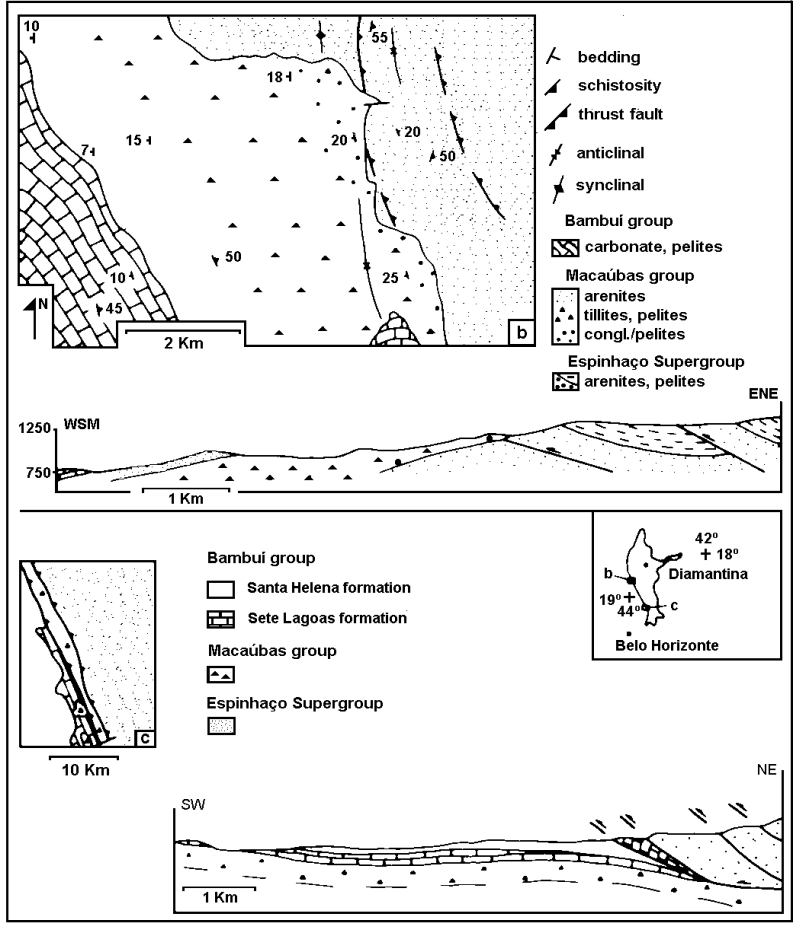

Figura 11: Mapas e seções geológicas da borda ocidental da SdEM (para a fonte dos dados, consultar Almeida Abreu 1993). Note que a deformação cresce sensivelmente de norte para sul ao longo dessa faixa.

Figure 11: Maps and cross-sections of the western SdEm (for data sources see Almeida Abreu 1993).

Note the increasing deformation from north to the south.

unidades glaciogênicas do Grupo Macaúbas.

A idade desse fenômeno glacial foi estimada em aproximadamente 1.055 Ma por D'Agrella-Filho et al. (1990), através de estudos de paleomagnetismo efetuado em rochas vulcânicas básicas do litoral sul da Bahia, onde constataram que o Craton do São Francisco passou pelos paralelos $40^{\circ}$ a $65^{\circ}$ norte no referido período.

Fica evidente, portanto, a coerência das relações estratigráficas entre as unidades do Supergrupo Espinhaço e do Grupo Macaúbas versus as idades geocronológicas dos eventos metamórficos desse supergrupo que identificam o período de deformação do mesmo. Mas existe ainda outra notável evidência da orogênese mesoproterozóica da SdEM: cerca de $2,5 \%$ da superfície areal dessa serra é ocupada por rochas básicas (diabásios e microgabros) que aparecem encaixadas em litologias do Supergrupo Espinhaço já deformadas. Essas rochas básicas não foram retrabalhadas pelas "Geleiras Jequitaí" uma vez que não aparecem seixos das mesmas nos metatilitos. E não poderiam aparecer. Datação pelo método $\mathrm{U} / \mathrm{Pb}$ 
em zircão e badeleíta de rocha básica pós-tectônica que aflora na região de Pedro Lessa mostra idade de $906 \pm 2$ Ma.

Notável também é a pronunciada discordância erosiva entre os grupos Macaúbas e Bambuí, uma vez que, nas bordas da Serra do Cabral e em partes da borda noroeste da SdEM, unidades desse último grupo assentam-se diretamente sobre litologias do Supergrupo Espinhaço (ver figuras 1, 9 e 11) ressaltando bem o lapso de tempo entre a sedimentação das unidades glaciogênicas (1.055 Ma) e das unidades carbonáticas do Grupo Bambuí (pós - 906 Ma).

O magmatismo de caráter básico que se impôs na SdEM por volta de $906 \mathrm{Ma}$ é representante, sem sombra de dúvidas, de um importante fenômeno geológico. Conforme discutido anteriormente e largamente documentado na literatura internacional, a amalgamação das massas continentais provoca o isolamento do calor mantélico (Gurnis 1988) o que, em pouco tempo, leva a geração de mantle plumes (Anderson 1982), cuja consequência é o desenvolvimento de intenso vulcanismo com distensão crustal associada (Burke \& Dewey 1973). Um supercontinente formado no fim do Mesoproterozóico é reportado por Barley \& Groves (1992), Moores (1993), Maruyama (1994), entre outros. Por outro lado, um evento de dispersão e fragmentação continental é registrado pelas razões de ${ }^{87} \mathrm{Sr} /{ }^{86} \mathrm{Sr}$ em carbonatos de diferentes orógenos (Veizer et al. 1983), concomitante $(\sim 900 \mathrm{Ma})$ ao vulcanismo basáltico pós-tectônico da SdEM.

Pelo exposto, pode-se pressupor que o vulcanismo em questão marca o início da distensão crustal que determinou a formação das bacias neoproterozóicas. No domínio leste do Craton do São Francisco essa bacia é representada pelas unidades do Grupo Bambuí, mas deve ser ressaltado, no entanto, que afloram apenas sequências depositadas numa plataforma plana e estável (mar epicontinental) sem qualquer representante de fácies de off-shore ou oceânicas de semelhante idade, nem no domínio cratônico, nem na SdEM e, ao que parece, tampouco na área que estendese até o litoral da costa atlântica adjacente. Portanto, não é exagero supor que o mar epicontinental da Bacia Bambuí mantinha conexão com a bacia da atual costa ocidental da Africa, em particular com a bacia da Faixa Oeste-Congolesa.

As discussões acerca da origem e situação geológica das unidades dos grupos Macaúbas e Bambuí são, portanto, de grande importância para o entendimento da evolução geotectônica da Serra do Espinhaço. Esta serra cavalga unidades dos referidos grupos em alguns domínios da sua borda ocidental e como pode ser visto nas seções e mapas da Figura 11, o avanço das rochas do Supergrupo Espinhaço sobre as litologias dos grupos Macaúbas e Bambuí ocorreu justo nos domínios mais deformados da SdEM (compare as Figuras 9 e 11), indicando que o Orógeno Espinhaço foi reativado no fim do Neoproterozóico, seguindo a mesma compartimentação da deformação deixada pela orogênese do Mesoproterozóico.

A unidade de topo do Grupo Bambuí (Formação Tres Marias) mostra sedimentos de ambiente marinho raso e de ambientes fluviais braided (Uhlein $1991 \mathrm{e}$ referências por ele citadas), o que deve representar uma significativa regressão marinha e indicando, assim, que essa formação registra uma fase de epirogênese que precedeu o fenecimento da bacia epicontinental onde depositaram-se as unidades do Grupo Bambuí. Essa regressão marinha deve ter ocorrido antes de 680 Ma uma vez que, entre 550 e 680 Ma são conhecidos depósitos glaciais em todos os continentes (inclusive na Faixa Paraguaia brasileira - Alvarenga \& Trompette 1992) e em diferentes paleolatitudes (inclusive em domínios equatoriais Chumakov \& Elston 1989).

Considerando que a inversão da Bacia OesteCongolesa teve início em aproximadamente $750 \mathrm{Ma}$ (Maurin et al. 1991, Pedrosa-Soares et al. 1992) e que eventos dessa natureza alteram a densidade das placas litosféricas (Cathles \& Hallam 1991) provocando a epirogênese das mesmas (Gurnis 1988), torna-se razoável admitir que antes de $700 \mathrm{Ma}$ a parte do Craton do São Francisco ocupada pelo Grupo Bambuí foi elevada acima do nível do mar.

A crosta continental tem capacidade efetiva de transmitir a deformação imposta por compressão da mesma (England \& McKenzie 1982) sendo as fases de colisão continental dos processos orogênicos a causa dessa deformação.

Um conspícuo aquecimento termal, com deformação associada, ocorreu no final do Neoproterozóico (Ciclo Brasiliano) e é fartamente documentado em vários domínios das faixas que bordejam o Craton do São Francisco (Siga Jr. et al. 1987, Teixeira et al. 1990, Uhlein 1991, e referências citadas nesses artigos). A SdEM e a Faixa Araçuaí registraram ambos: o aquecimento termal e a deformação, que manifestou-se como reativação tectônica, motivando o cavalgamento das unidades da entidade orogenética mesoproterozóica (Supergrupo Espinhaço) sobre unidades mais novas (grupos Macaúbas e Bambuí).

A fase final da orogênese Pan-Africana (fase colisional) imposta à Faixa Oeste-Congolesa ocorreu no período de 500 - 600 Ma (Maurin et al. 1991). Quando dessa colisão, a Faixa Oeste-Congolesa situava-se a cerca de $500 \mathrm{~km}$ de distância da SdEM, distância esta muito discreta no sentido da deformação imposta pela orogênese daquela faixa propagar-se, através da crosta, até um domínio já significativamente estruturado e com muitas zonas de fraqueza estabelecidas, que era a Serra do Espinhaço. A fase colisional dos Himalaias, a exemplo, transmitiu deformação intra-placa por mais de $1000 \mathrm{~km}$ de distância, indo reativar o Tien Shan (orógeno paleozóico da Ásia central - England \& McKenzie 1982, Windley et al. 1990).

O arranjo estrutural da Faixa Oeste-Congolesa (Maurin et al. 1991) indica, claramente, que se essa faixa, na sua fase de bacia, desenvolveu crosta oceânica, 


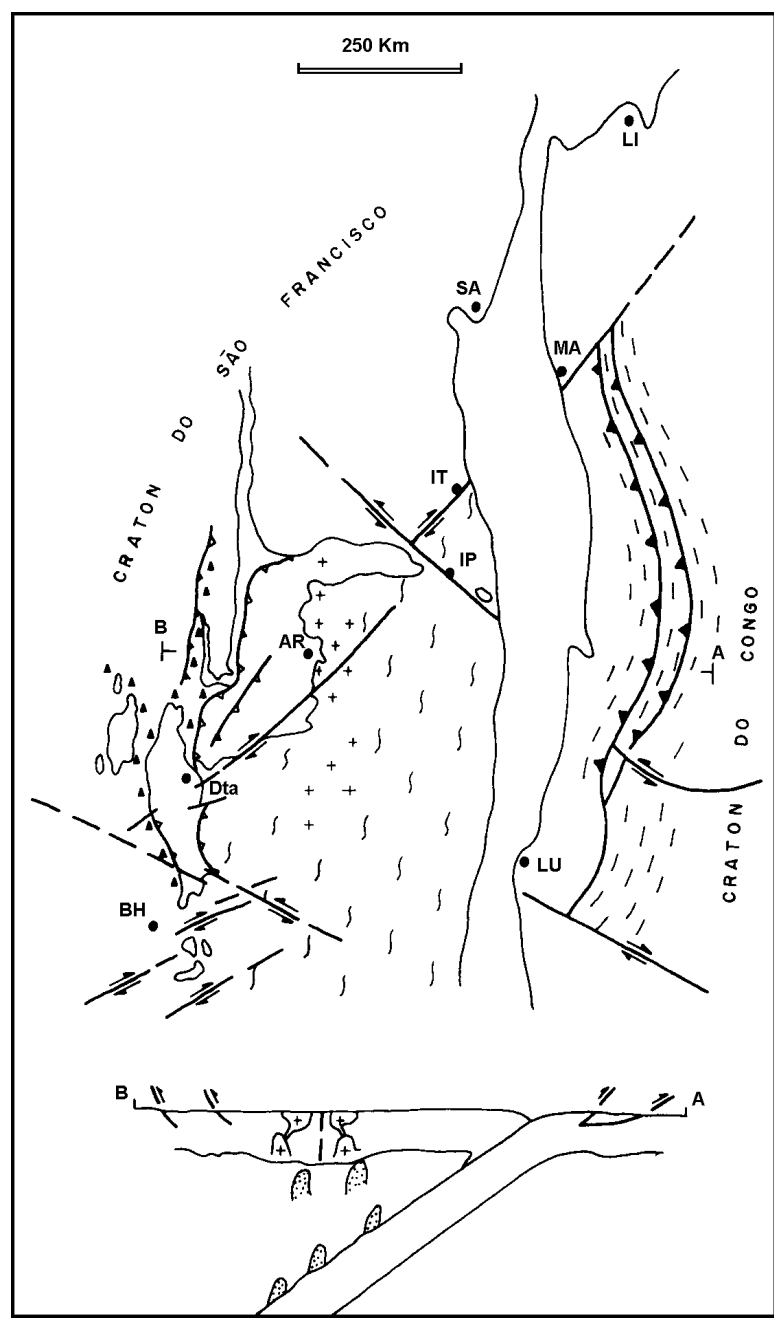

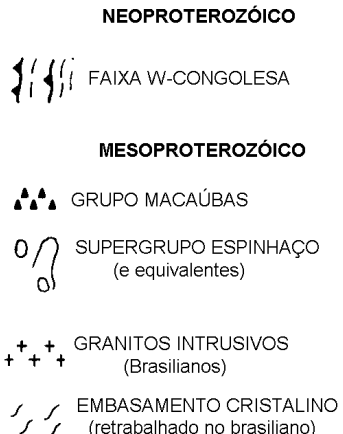

FALHAS MAIORES DO SISTEMA ESPINHAÇO ATIVAS OU REATIVADAS DURANTE A OREGÊNESE PAN-AFRICANA.

$$
\begin{aligned}
& \text { Falha InVERsa / CAVALgamento } \\
& \text { FalHa DE REJeIto diRECIONAL }
\end{aligned}
$$

$\begin{array}{ll}\text { AR - ARAÇUAI } & \text { BH - BELO HORIZONTE } \\ \text { Dta - DIAMANTINA } & \text { IP - ITAPEBI } \\ \text { IT - ITABUNA } & \text { LI - LIBREVILLE } \\ \text { LU - LUANDA } & \text { MA - MAYUMBA } \\ \text { SA - SALVADOR } & \end{array}$

SA - SALVADOR

- SEÇÃO ESQUEMÁTICA (HIPOTÉTICA) MOSTRANDO SUBDUCÇÃO DA LITOSFERA OCEÂNICA DA MARGEM

Figura 12: Mapa esquemático (modificado de Pedrosa Soares et al. 1992) mostrando a situação paleogeográfica da Faixa Oeste-Congolesa na sua fase final de orogênese (colisão continental), que foi responsável pela reativação tectônica do Sistema Espinhaço no fim do Neoproterozóico. A seção (segundo Almeida Abreu 1993) ilustra a subducção da crosta oceânica da Bacia Oeste-Congoleasa sob a região sudeste do Craton do São Francisco, provocando extenso plutonismo granítico e aquecimento termal nessa região.

Figure 12: Schematic map (modified from Pedrosa Soares et al. 1992) showing the paleogeographic situation of the West-Congolian belt at the end of the orogenic phase (continental collision), which was reponsible for the tectonic reactivation of the Espinhaço system during late Neoproterozoic. The cross-section (after Almeida Abreu 1993) shows the oceanic crust subduction of the West-Congolian basin under the southeastern São

Francisco Craton, causing extensive granitic plutonism and thermal heating in this region.

esta sofreu, durante o Ciclo Orogenético PanAfricano, subducção para oeste mergulhando, portanto, sob o Craton do São Francisco (Fig. 12). E, se assim, pode-se explicar: 1) $\mathrm{O}$ aquecimento termal imposto a todo o domínio sudeste desse craton no final do Neoproterozóico; 2) os plutons graníticos que ocorrem em diferentes áreas da referida região.

Como já foi dito anteriormente, de W para E, da Serra do Espinhaço em direção aos domínios orientais da Faixa Araçuaí, ressalta-se, nas rochas dessa faixa, um metamorfismo barroviano crescente (PedrosaSoares et al. 1992) relacionado, provavelmente, à orogênese mesoproterozóica. Na região de Araçuaí Itinga, o metamorfismo barroviano é subitamente substituído por metamorfismo de alta temperatura e baixa pressão (Costa 1992) e, não por coincidência, nessa área aparecem volumosos batólitos graníticos de idade neoproterozóica (Fig. 12).

\section{REFERÊNCIAS BIBLIOGRÁFICAS}

ALMEIDA ABREU, P. A. - 1989 - Geologia das quadrículas Onça e Cuiabá (Gouveia-MG) - região mediana central da Serra do Espinhaço Meridional. Diss. Mestrado. Rio de Janeiro. UFRJ, Inst. Geoc., 75p. (inédito).

ALMEIDA ABREU, P. A. - 1993 - A evolução geodinâmica da Serra do Espinhaço Meridional, Minas Gerais, Brasil. Diss. Doutorado. Freiburg (Alemanha) Univ. Freiburg, Geol. Inst. 150 p. (inédito).

ALMEIDA ABREU, P. A. \& PFLUG, R. - 1992 - Geodynamic evolution of the southern Serra do Espinhaço, Minas Gerais, Brazil. Part I: The Basin. In: GEOWISSENCHAFTLICHES LATEINAMERIKAKOLLOQUIUM, 13, Münster, 1992. Abstracts... Münster, Westfälische Wilhelms-Universität Münster (Alemanha), p. 1.

ALMEIDA ABREU, P. A. \& PFLUG, R. - 1994 - The geodynamic evolution of the southern Serra do Espinhaço, Minas Gerais, Brazil. Zbl. Geol., H1/2: 21- 44. 
ALVARENGA, C. J. S. de \& TROMPETTE, R. - 1992 - Glacially influenced sedimentation in the Later Proterozic of the Paraguay belt (Mato Grosso, Brazil). Palaeog., Palaeoc., Palaeoec., 92: 85105

ANDERSON, D. L. - 1982 - Hotspots, polar wander, Mesozoic convection and the geoid. Nature, 297: 391-393.

BARLEY, M. E. \& GROVES, D. I. - 1992 - Supercontinent cycles and the distribution of metal deposits through time. Geology, 20: 231294

BIRD, P. - 1979 - Continental delamination and the Colorado Plateau. J. Geoph. Res., 84: 7561-7571.

BLITZKOW, D.; GASPARINI, P;SA, N. C. de \& MONTOVANI, M. S. M. - 1979 - Crustal structure of southeastern Minas Gerais, Brazil, deduced from gravity measurements. Rev. Bras. Geoc., 9: 39-43.

BOILLOT, G.; FÉRAUD, G.; RECQ, M. \& GIRARDEAU, J. - 1989 Undercrusting by serpentinite beneath rifted margins. Nature, 341:523-525.

BOSWORTH, W. - 1985 - Geometry of propagating continental rifts. Nature, 316: 625-627.

BUCK, W. R. - 1988 - Flexural rotation of normal faults. Tectonics, 7: 353-373.

BURKE, K. \& ASHWAL, L. d. - 1989 - Plate tectonics and thermal behavior of the Earth during the Precambrian. In: INTERN. GEOL. CONGR., 28th., Washington, 1990. Abstracts ... Washington, v. 1, p. 216.

BURKE, K. \& DEWEY, J. F. - 1973 - Plume-generated triple junctions: Key indicators in applying plate tectonics to old rocks. J. Geol., 81:406-433.

CATHLES, L. M. \& HALLAM, A. - 1991 - Stress-induced changes in plate density, Vail sequences, epeirogeny, and short-lived global sea level fluctuation. Tectonics, 10: 659-671.

CHULA, A. M. D.; KNAUER, L. G. \& ALMEIDA ABREU, P. A. - 1995 - Considerações sobre a geologia da região de Desembargador Otoni - Planalto de Minas, Diamantina (MG). In: SIMP. GEOL. MINAS GERAIS, 8, Diamantina, 1995. Anais... Belo Horizonte, SBG/MG, no prelo.

CHUMAKOV, N. M. \& ELSTON, D. P. - 1989 - The paradox of Late Proterozoic glaciations at low latitudes. Episodes, 12: 115-120.

COBBOLD, P.R.; GAPAIS, D. \& ROSSELLO, E. A. - 1991 -Partitioning of transpressive motions within a sigmoidal foldbelt: The Variscan Sierras Australes, Argentina. J. Struct. Geol., 13: 743-758.

CONEY, P. J. - 1980 - Cordilleran metamorphic core complexes: An overview. Geol. Soc. Am., Memoir 153: 7-31.

CORDANI, U. G.; IYER, S. S.; TAYLOR, P. N.; KAWASHITA, K.; SATO, K. \& McREATH, I. - 1992 - Pb-Pb, Rb-Sr, and K-Ar systematics of the Lagoa Real uranium province (south-central Bahia, Brazil) and the Espinhaço Cycle (ca. 1.5 -1.0 Ga). J. South Am. Earth Sci., 5: 33-46.

COSTA, A. G. - 1992 - Minerais como indicadores de um tipo de metamorfismo: um exemplo da região de Utinga, médio vale do Rio Jequitinhonha - MG. Rev. Escola de Minas, 45: 167-169.

D'AGRELLA-FILHO, M. S.; PACCA, I. G.; TEIXEIRA, W.; ONSTOTT, T. C. \& RENNE, P. R. - 1990 - Paleomagnetic evidence for the evolution of Meso- to Neo-Proterozoic rocks in central-eastern Brazil. Palaeog., Palaeoc., Palaeoec., 80: 255-265.

DAVIS, G. H. - 1983 - Shear-zone model for the origin of metamorphic core complexes. Geology, 11:342-347.

DOSSIN,I. A.; CHAVES, M.L. de S. C.; UHLEIN, A. \& ALVARENGA, C. J. de S. - 1985 - Geologia e depósitos diamantíferos da região de Sopa, Diamantina-MG. In: SIMP. GEOL. MINAS GERAIS, 3, Belo Horizonte, 1985. Anais... Belo Horizonte, SBG/MG, Bol. 5, p. 276-290.

DOSSIN,I.A.; DOSSIN, T.M.; CHARVET, J.; COCHERIE, A. \& ROSSI, P. - 1993 - Single-zircon dating by step-wise Pb evaporation of Middle Proterozoic magmatism in the Espinhaço Range, Southeastern São Francisco Craton (Minas Gerais, Brazil). In: SIMP. CRATON SÃO FRANCISCO, 2, Salvador, 1993. Anais... Salvador, SBG/Ba - SGM/Ba, p. 39-42.

ENGLAND, P. \& McKENZIE, D. - 1982 - A thin viscous sheet model for continental deformation. Geophys. J. R. Astr. Soc., 70: 295321

FOGAÇA, A. C. C.; ALMEIDA ABREU,P. A. \& SCHORSCHER, H.D. -1984 - Estratigrafia da sequência supracrustal arqueana na porç̃a mediana central da Serra do Espinhaço-MG. In: CONGR. BRAS.
GEOL., 33, Rio de Janeiro, 1984. Anais... Rio de Janeiro, SBG, v.2, p. 2652-2667.

GALER, S. J. G. - 1991 - Interrelationships between continental freeboard, tectonics and mantle temperature. Earth Plan. Sci. Lett., 105:214-228.

GURNIS, M. - 1988 - Large-scale mantle convection and the aggregation and dispersal of supercontinent. Nature, 332: 695699.

HOFFMANN, C. - 1983 - The Archean peraluminous Gouveia Granite: Its structure, geochemistry and phase petrology (Serra do Espinhaço, Minas Gerais, Brazil). N. Jb. Miner. Abh., 146: 359371.

HOPPE, A. - 1986 - Geodynamic evolution of an Early to MidProterozoic mountain range: The Serra do Espinhaço, centraleastern Brazil. In: GEOCONGRESS ' 86 - 21 st. BIANN. CONGR. GEOL. S. AFRICA, Johannesburg, 1986. Ext. Abstr. ... Johannesburg, p. 307-309.

HOUSEMAN, G. \& ENGLAND, P. - 1986 - A dynamical model of lithosphere extension and sedimentary basin formation. J. Geoph. Res., 91: 719-729.

HOWELL, P. D. \& van der PLUIJM, B. A. - 1990 - Early history of the Michigan basin: Subsidence and Appalachian tectonics. Geology, 18: 1195-1198.

HYNES, A. - 1982 - Stability of the oceanic tectosphere - A model for early Proterozoic intercratonic orogeny. Earth Plan. Sci. Lett., 61: 333-345.

ILLIES, J. H. - 1981 - Mechanism of graben formation. Tectonophysics, 7:249-266.

JACKSON, M. J.; SIMPSON, E. L. \& ERIKSSON, K. A. - 1990 - Facies and sequence stratigraphic analysis in an intracratonic thermalrelaxation basin: The Early Proterozoic, Lower Quilalar Formation and Ballara Quartzite, Mount Isa Inlier, Australia. Sedimentology, 37: $1053-1068$

KASTINGS, J. F. - 1989 - Long-term stability of the Earth's climate. Palaeog., Palaeocl., Palaeoec., 75: 83-95.

KNAUER, L. G. - 1990 - Evolução Geológica do Pré-Cambriano da porção centro-leste da Serra do Espinhaço Meridional e metalogênese associada. Diss. Mestrado. Campinas. UNICAMP, Dept. Geoc., 298p. (inédita).

KÖSTER, J. - 1984 - Geologie der nordwestlichen Serra Mineira, sudöstlichen von Buenópolis (Proterozoikum, Serra do Espinhaço, Minas Gerais, Brasilien). Diplomarbeit Freiburg (Alemanha) Univ. Freiburg, Geol. Inst., 85 p. (inédito).

KUMAZAWA, M. \& MARUYAMA, S. - 1994 - Whole Earth tectonics. J. Geol. Soc. Japan, 100: 81-102.

LEEDER, M. R.; ORT, D. M. \& COOLIER, R. - 1988 - Development of fluvial and fan deltas in neotectonic extensional settings: Implications for the interpretations of basin-fills. In: NEMEC, W.; STEEL, R. J. (eds.), 1988. Fan Deltas: Sedimentology and tectonic settings. London. Blackie. p. 173-185.

LEMOINE, M.; TRICARD, P. \& BOILLOT, G. - 1987 - Ultramafic an gabbroic ocean floor of the Ligurian Tethys (Alps, Corsica, Apennines): In search of a genetic model. Geology, 15: 622-625.

MACHADO, N.; FENG, R. \& NOCE, C. M. - 1993 - Datação U-Pb de zircões de sequênecias proterozóicas na região do Quadrilátero Ferrífero, borda sul do Craton do São Francisco: considerações sobre áreas-fonte e idades de sedimentação. In: SIMP. CRATON SÃO FRANCISCO, 2, Salvador, 1993. Anais... Salvador, SBG/Ba -SGM/Ba, p.149-151.

MACHADO, N.; SCHRANK, A.; ABREU,F. R. de; KNAUER, L. G. \& ALMEIDA ABREU, P. A. - 1989 - Resultados preliminares da geocronologia U/Pb na Serra do Espinhaço Meridional. In: SIMP. GEOL. MINAS GERAIS, 5, Belo Horizonte, 1989. Anais... Belo Horizonte, SBG/MG. Bol. 10, p. 171-174.

MARTINS NETO, M. A. - 1993 - The sedimentary evolution of a Proterozoic rift basin - The basal Espinhaço Supergroup, southern Serra do Espinhaço, Minas Gerais, Brazil. Diss. Doutorado. Freiburg (Alemanha). Univ. Freiburg, Geol. Inst., (inédita).

MARUYAMA, S. - 1994 - Plume tectonics. J. Geol. Soc. Japan, 100 $24-49$.

MAURIN, J-C.; BOUDZOUMOU, F.; DJAMA, L-M.; GIOAN, P.; MICHARD, A.; MPEMBA-BONI, J.; PEUCAT, J-J.; PIN, C. \& VICAT, J-P. -1991 - La chaîne proterozoïquest-congolienne et son avant-pays au Congo: nouvelles données 
géochronologiques et struturales, implications en Afrique centrale. C. R. Acad. Sci. Paris, 312: 1327-1334.

MOORES, E. M. - 1993 - Neoproterozoic oceanic crust thinning, emergence of continents, and origin of the Phanerozoic ecosystem: A model. Geology, 21: 5-8.

NELSON, R. A.; PATTON, T. L. \& MORLEY,C. K. - 1992 - Rift-segment interaction and its relation to hydrocarbon exploration in continental rift systems. Am. Ass. Petrol. Geol. Bull., 76: 11531169

NESBITT, H. W. \& YOUNG, G. M. - 1984 - Prediction of some weathering trends of plutonic and volcanic rocks based on thermodynamic and kinetic considerations. Geoch. Cosmoch. Acta, 48: 1523-1534.

NICHOLLS, I. A.; FERGUSON, J.; JONES, H.; MARKUS, G. P. \& MUTTER, J. C. - 1981 - Ultramafic blocks from ocean floor southwest of Australia. Earth Plan. Sci. Lett., 56: 362-374.

PARRISH, J.T. \& BARRON, E.J. - 1986 - Paleoclimates and economic geology. Soc. Econ. Petrol. Miner., Short Course 18, 162 p.

PEDROSA SOARES, A. C.; NOCE, C. M.; VIDAL, Ph.; MONTEIRO, R. L. B. P. \& LEONARDOS, O. H. - 1992 - Towards a new tectonic model for the Late Proterozoic Araçuaí (SE Brazil) - West Congolian (SW Africa) belt. J. South Am. Earth Sci., 6: 33-47.

PLATT, J. P.; BEHRMANN, J. H.; CUNNINGHAM, P. C.; DEWEY, J. F.; HELMAN, M.; PARISH, M.; SHEPLEY, M. G.; WALLIS, S. \& WESTON, P. J. - 1989 - Kinematics of the Alpine arc and the motion history of Adria. Nature, 337: 158-161.

PFLUG, R. - 1968 - Observações sobre a estratigrafia da Série Minas na região de Diamantina, MG; DNPM, RJ - Notas Preliminares e Estudos, (142); 20p.

RENGER, F. - 1979 - Evolução dos conceitos geológicos da Serra do Espinhaço. In: SIMP. GEOL. MINAS GERAIS, 1, Diamantina, 1979. Atas... Belo Horizonte, SBG/MG, Bol. 1, p. 9-28.

RODRIGUES DA SILVA, R. - 1995 - Contributions to the stratigraphy and paleogeography of the Lower Espinhaço Supergroup (Mesoproterozoic), between Diamantina and Gouveia, Minas Gerais, Brazil. Diss. Doutorado, Geol. Inst. Univ. Freiburg (Alemanha), $115 \mathrm{p}$.

RODRIGUES DA SILVA, R \& TOLEDO, C. L. B - 1994 - A Proterozoic duplex thrust system in the southern Serra do Espinhaço Minas Gerais, Brazil. Zbl. Geol. Paläont., H 1/2: 55-66.

ROYDEN, L.; SCLATER, J. G. \& von HERZEN, R. P. - 1980 -Continental margin subsidence and heat flow: Important parameters in formation of petroleum hydrocarbons. Am. Assoc. Petrol. Geol. Bull., 64: 173-187.

SIGA Jr., O.; CORDANI, U. G.; KAWASHITA, K.; BASEI, M. A. \& TAYLOR, P. N. - 1987 - Aplicação dos isótopos de $\mathrm{Sr}$ e Pb nas rochas gnáissicas-migmatíticas de Itacambira-Barrocão. In: SIMP.
GEOL. MINAS GERAIS, 4, Belo Horizonte, 1987. Anais... Belo Horizonze, SBG/MG Bol.7, p. 45-57.

SCHOBBENHAUS, C; HOPPE, A.; BAUMANN, A. \& LORK, A. 1984 -Idade U/Pb do vulcanismo Rio dos Remédios, Chapada Diamantina, Bahia. In: CONGR. BRAS. GEOL., 38, Balneário Camboriú, 1994. Bol. Res. Expandidos... Balneário Camboriú, SBG, p. 397-399.

SCHÖLL, W. V. \& TURINSKY, F. - 1980 - O espectro dos minerais pesados nas sequências quartzíticas pré-cambrianas na parte sul da Serra do Espinhaço, Minas Gerais, Brasil. Münster Forsch. Geol. Paläont., 51: 257-278.

SCHUMM, S. A. - 1968 - Speculations concerning paleohydrologic controls of terrestrial sedimentation. Geol. Soc. Am. Bull., 9: 15731588

SPENCER, J. E. - 1984 - Role of tectonic denudation in warping and uplift of low-angle normal faults. Geology, 12: 95-98.

SOUTHWICK, D. L.; MOREY, G. B. \& MOSSLER, J. H. - 1986- Fluvial origin of the Lower Proterozoic Sioux Quartzite, Southwestern Minnesota. Geol. Soc. Am. Bull., 97: 1432-1441.

TANKARD, A. J.; JACKSON, M. P. A.; ERIKSSON, K. A.; HOBDAY, D.K.; HUNTER, D. R. \& MINTER, W. E. L. - 1982 - The earliest red beds. In: Crustal evolution of southern Africa - 3.8 billion year of Earth history. New York, Springer-Verlag, p. 203-216.

TEIXEIRA, W.; DOSSIN, I. A.; DOSSIN, T. M.; SALVADOR, E. D.; SIGA Jr., O. \& SATO, K. - 1990 - Interpretação do contexto geotectônico do embasamento na borda leste do Sistema Espinhaço, região de Guanhães e Gouveia-MG, com base numa integração do seu conjunto geocronológico U/Pb, Rb/Sr e K/Ar. In: CONGR. BRAS. GEOL., 36, Natal, 1990. Anais... Natal, SBG, v. 6,p. 2711-2722.

THOMPSON, A. B. \& ENGLAND, P. C. - 1984 - Pressure-temperaturetime paths of regional metamorphism II. Their inference and interpretation using mineral assemblages in metamorphic rocks. J. Petrol., 25: 929-955.

UHLEIN, A. - 1991 - Transição cráton - faixa dobrada: exemplo do Cráton do São Francisco e da Faixa Araçuaí (Ciclo Brasiliano) no Estado de Minas Gerais. Aspectos estratigráficos e estruturais. Diss. Doutorado. São Paulo. USP, Inst. Geoc., 295 p. (inédita).

VEIZER, J; COMPSTON, W.; CLAUER, N. \& SCHIDLOWSKI, M. $1983-{ }^{87} \mathrm{Sr}{ }^{86} \mathrm{Sr}$ in Late Proterozoic carbonates: Evidence for a "mantle event" at $\approx 900$ Ma ago. Geoch. Cosmoch. Acta, 47: 295302.

VIALON, P.; ROCHETTE, P. \& MENARD, G. - 1989- Indentation and rotation in the western Alpine arc. Geol. Soc., Sp. Publ., 45: 329338

WANG, C. \& SUN, Y. - 1994 - Development of Paleogene depressions and deposition of lacustrine source rocks in the Pearl River Mouth Basin, northern margin of the South China Sea. Am. Assoc. Petrol. Geol. Bull., 78: 1711-1728.

WINDLEY, B. F.; ALLEN, M. B.; ZHANG, C.;ZHAO,Z-Y.\& WANG, G-R. - 1990 - Paleozoic accretion and Cenozoic redeformation of the Chinese Tien Shan range, central Asia. Geology, 18: 128-131. 